\title{
La era de Trump y sus impactos en la frontera norte de México
}

Dirección General Noroeste,

El Colegio de la Frontera Norte (El Colef)

Varios autores

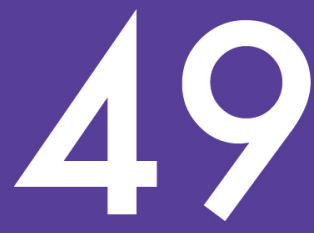

ENERO/FEBRERO 2019

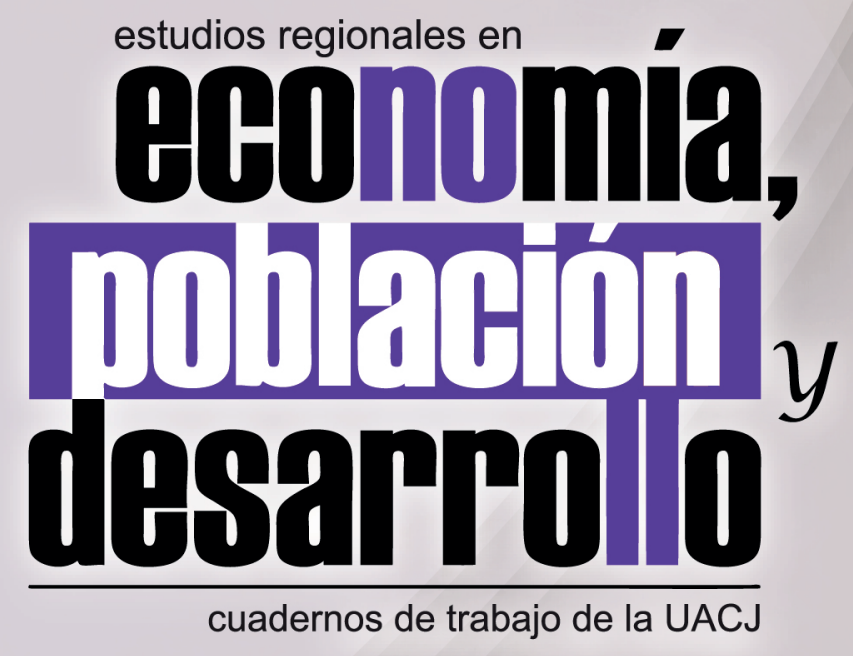




\section{La era de Trump y sus impactos en la frontera norte de México}

Dirección General Noroeste, El Colegio de la Frontera Norte (El Colef).

Varios autores 


\title{
UNIVERSIDAD AUTÓNOMA DE CIUDAD JUÁREZ RED IBEROAMERICANA DE ESTUDIOS DEL DESARROLLO
}

\author{
Cuerpo Académico de Estudios Regionales en \\ Economía, Población y Desarrollo
}

Universidad Autónoma de Ciudad Juárez

2018-2024

Mtro. Juan Ignacio Camargo Nassar

Rector

Mtro. Daniel Alberto Constandse Cortez

Secretario General

Mtro. Jesús Meza Vega

Director General de Comunicación Universitaria

Dra. Beatriz Araceli Díaz Torres

Coordinadora General de Investigación y Posgrado

Comité de Coordinación de la Red Iberoamericana de Estudios del Desarrollo 2018-2020

Dra. Paulina Sanhueza Martínez (Universidad de la Frontera, Chile)

Coordinadora General

Dr. Ignacio Rodríguez Rodríguez (Universidad de la Frontera, Chile)

Secretario general

Dra. Myrna Limas Hernández

(Universidad Autónoma de Ciudad Juárez, México)

Vocal de Organización

Dr. Pablo Galaso Reca (Universidad de la República, Uruguay)

Vocal de Organización

Dr. Luis Enrique Gutiérrez Casas

Director y editor de Cuadernos de Trabajo

Estudios Regionales en Economía, Población y Desarrollo

Comité editorial Sección internacional

Dra. Sofía Boza Martínez (Universidad de Chile, Chile) Dra. Olga Biosca Artiñano

(Glasgow Caledonian University, Reino Unido)

Dra. Ángeles Sánchez Díez

(Universidad Autónoma de Madrid, España)

Dr. Thomas Fullerton Mankin

(University of Texas at El Paso, Estados Unidos)

Dr. Adrián Rodríguez Miranda

(Universidad de la República, Uruguay)

Sección local

(Universidad Autónoma de Ciudad Juárez)

Dra. Myrna Limas Hernández

Dra. Ikuho Kochi

Dr. Raúl Alberto Ponce Rodríguez

Dr. Isaac Leobardo Sánchez Juárez

Dr. Héctor Alonso Barajas Bustillos

Diseño de cubierta Abigail Bautista
Estudios Regionales en Economía, Población

y Desarrollo. Cuadernos de Trabajo de la UACJ

ISSN 2007-3739

Número 49. Enero/Febrero 2019

La era de Trump y sus impactos en la

frontera norte de México

Dirección General Noroeste, El Colegio de la Frontera Norte (El Colef).

Varios autores

$$
\text { Universidad Autónoma de Ciudad Juárez }
$$

Estudios Regionales en Economía, Población y Desarrollo. Cuadernos de Trabajo de la UACJ

Año 9, No. 49 enero-febrero 2019, es una publicación bimestral editada por la Universidad Autónoma de Ciudad Juárez a través del Cuerpo Académico de Estudios Regionales en Economía, Población y Desarrollo del Instituto de Ciencias Sociales y Administración. Redacción: Avenida Universidad y H. Colegio Militar, Zona Chamizal s/n., C.P. 32300, Ciudad Juárez, Chihuahua, México. Teléfonos: (656) 688-38-00, ext. 3792. Correo electrónico:1gtz@uacj.mx.

Editor responsable: Luis Enrique Gutiérrez Casas. Reserva de derechos al uso exclusivo No. 04-2011-021713353900-102. ISSN 2007-3739, Impresa por Studio Los Dorados, calle Del Campanario, número 820-2, Santa Cecilia, C.P. 32350, Cd. Juárez, Chihuahua. Distribuidor: Subdirección de Gestión de Proyecto y Marketing Editorial. Ave. Plutarco Elías Calles 1210, Foviste Chamizal, C.P. 32310, Ciudad Juárez, Chihuahua. Este número se terminó de imprimir el 15 de diciembre, 2018 con un tiraje de 120 ejemplares.

Los ensayos publicados son responsabilidad exclusiva de sus autores. Se autoriza la reproducción total o parcial bajo condición de citar la fuente.

\section{Registrada en: EBSCO RePEC}

Publicación afiliada a la Red Iberoamericana de Estudios del Desarrollo

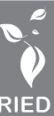

Universidad Autónoma de Ciudad Juárez

Ave Plutarco Elías Calles 1210

Foviste Chamizal, C.P. 32310

Ciudad Juárez, Chihuahua, México

www.uacj.mx

(C) Universidad Autónoma de Ciudad Juárez 


\title{
La era de Trump y sus impactos en la frontera norte de México
}

\author{
Dirección General Noroeste, El Colegio de la Frontera Norte (El Colef). \\ Varios autores *
}

\section{Resumen}

A partir del triunfo como presidente de Estados Unidos de Donald Trump, al que le anteceden discursos reaccionarios y polémicos en temas sensibles entre México y Estados Unido, se hace obligado el planteamiento de posibles de escenarios en materia política, social, económica y ambiental para la frontera norte de México. Un grupo de investigadores de El Colegio de la Frontera Norte (México) se reunió para reflexionar sobre estos temas y elaborar algunas recomendaciones para los tomadores de decisiones, en particular para los gobiernos de los seis estados de la frontera norte de México. En este cuaderno de trabajo se presentan algunas de sus reflexiones.

Palabras clave: Frontera norte de México, Trump, política pública, relaciones México-Estados Unidos.

\begin{abstract}
From the triumph of Donald Trump as President of the United States, and considering his reactionary and controversial speeches on sensitive issues between Mexico and the United States, it is necessary to explore on possible scenarios concerning political, social, economic and environmental issues that may have significant impacts on the northern border of Mexico. A group of researchers from the El Colegio de la Frontera Norte (Mexico) met to dialogue on these issues and make recommendations of public policy mainly oriented to decision-makers of the six Mexican Border States governments. Some of these ideas are discussed in this working paper.
\end{abstract}

Keywords: Northern border of Mexico, Trump, public policy, United States-Mexico relations. JEL Classification: R11, R58, Y80.

Recibido en: Agosto de 2018.

- Aprobado en: Noviembre 2018.

* Los(as) autores(as) de este número son investigadores(as) de El Colegio de la Frontera Norte, México. 


\section{$\rightarrow$ 1. Introducción.}

A partir del triunfo como presidente de Estados Unidos de Donald Trump que le anteceden discursos reaccionarios y polémicos en temas sensibles entre México y Estados Unido, se hace obligado el planteamiento de posibles de escenarios en materia política, social, económica y ambiental para la frontera norte de México. Para dicho planteamiento se conjuntó un grupo de investigadores de El Colegio de la Frontera Norte para reflexionar sobre estos temas y elaborar algunas recomendaciones para los tomadores de decisión, en particular para los gobernadores de los seis estados de la Frontera Norte por la relevancia que enmarca esta región.

La Frontera entre México y Estados Unidos tiene una extensión de 3,141 kilómetros, la cual incluye desde las poblaciones que se localizan junto al Océano Pacífico hasta las que se ubican en el Golfo de México. Una de las definiciones más usadas de la región fronteriza es la propuesta durante la firma de los Acuerdos de La Paz en 1983, en donde ésta área se define como una franja de tierra de 100 kilómetros a ambos lados de la división internacional. En este contexto, el área fronteriza incluye 48 condados de 4 estados de Estados Unidos y 94 municipios en 6 estados de México y 15 pares de ciudades hermanas (PAHO, 2012). La región fronteriza es la materialización física, social y económica de la globalización donde ocurren procesos de interrelación e intercambio con flujos aproximados en 2015 de 74.2 millones de vehículos personales, 5.5 millones de camiones de carga, y 41.2 millones de peatones (U.S. Bureau of Transport Statistics, 2015)1 ${ }^{1}$, comercio bilateral de 500,000 millones de dólares aproximadamente el cual cruza a través de cruces terrestres siendo para Estados Unidos el segundo socio comercial a nivel mundial.

Es significativo también que la frontera México-Estados Unidos muestra una dinámica única en el mundo en cuestión de la cantidad y diversidad de desplazamientos poblacionales, situándose como la frontera más transitada del mundo. A través de sus 58 cruces fronterizos, circulan diariamente más de un millón de personas y alrededor de 437 vehículos. A esta circulación cotidiana, se le suman más de 700 mil migrantes provenientes de México, Centroamérica y otras regiones de los cinco continentes que llegan año con año a esta región con intenciones de establecerse o en su trayecto hacia Estados Unidos.

Existen recursos naturales compartidos de gran relevancia como el agua a través de las cuencas hidrográficas del Bravo y El Colorado principalmente, razón por la cual existen instituciones binacionales como CILA y COCEF que promueven las buenas prácticas para el uso de estos recursos la frontera con mayores instituciones y organizaciones, tratados, acuerdos y convenios de colaboración binacional en materia ambiental.

\footnotetext{
${ }^{1}$ En https://transborder.bts.gov/programs/international/transborder/TBDR_BC/TBDR_BCQ.html.
} 
Es así que en esta frontera se encuentran en constante intercambio la primera economía del mundo (USA) y la décimo quinta, y juntas representan aproximadamente el 25\% del PIB mundial. El escenario se presenta no muy prometedor en los temas financieros y de relaciones internacionales con amenazas inminentes sobre la deportación de migrantes, la construcción de un muro fronterizo, el rechazo a las evidencias del cambio climático, la renegociación del TLCAN, la disminución del envío de remesas y el freno a la inversión extranjera. Por ello es necesario reflexionar sobre estos temas para identificar y proponer alternativas ante los retos que estos escenarios plantean a partir de la pregunta ¿Cuáles son los posibles impactos de la administración del presidente Donald Trump en la Frontera México-Estados Unidos? En este trabajo se busca dar respuesta a la pregunta planteada reflexionando de forma particular a través de temas claves para la región, tales como seguridad fronteriza, cooperación, relaciones internacionales, migración, cambio climático y recursos naturales compartidos.

Para ello, este documento se estructura de la siguiente manera, en primer término, se plantea la perspectiva biopolítica y psicopolítica de la frontera para reflexionar sobre las comunidades transfronterizas, posteriormente se aborda la problemática fronteriza desde la perspectiva de las relaciones internacionales y el resurgimiento del neorrealismo. A continuación, se abordan los temas particulares de seguridad, migración y medio ambiente. En cuanto a seguridad fronteriza se discute el posible impacto de la construcción del muro en el flujo de las drogas desde la perspectiva de la economía política ilícita.

En el tema de migración se contrasta la realidad de la migración irregular mexicana en la frontera México-Estados Unidos en relación con las acciones ejecutivas de Donald Trump en esta materia. Los últimos tres trabajos reflexionan sobre el tema ambiental en particular sobre el mantenimiento de las relaciones de cooperación hasta ahora construidas, la seguridad de los recursos hídricos y el cambio climático. 
- 2. Comunidades transfronterizas inmunizadas en la frontera México-Estados Unidos. Una mirada al nuevo entorno global desde la biopolítica y la psicopolítica.

Rigoberto García Ochoa²

Los que vivimos en la región fronteriza entre México-Estados Unidos vemos, en nuestra cotidianeidad, los profundos lazos económicos, comerciales, personales y culturales que existen en las comunidades de ambos lados de la frontera. Sentimos y palpamos, también, profundas diferencias. Racismo, xenofobia, rechazo a la otredad y la concreta y tangible implementación de mecanismos de control al flujo migratorio conforman una realidad que se ha perpetuado históricamente, aunque con diferentes grados de intensidad. La tensión entre una deseada -y nunca lograda- comunidad transfronteriza y una relación de proximidad sin contacto -o de plano rechazo-, se ha intensificado con la llegada de Donald Trump a la presidencia de Estados Unidos.

Esta situación dista mucho de ser un fenómeno regional, o incluso entre dos naciones. Es un fenómeno global. Previo a la llegada de Trump estuvo el Brexit, el rechazo al Acuerdo Transpacífico por parte de Estados Unidos y los brotes fascistas en Europa, sin olvidar el fundamentalismo islámico que proclama como verdad su exclusividad monoteísta. Después de 25 años de globalización económica como paradigma dominante, esto en comunión con un capitalismo neoliberal y financieramente obsceno, nos encontramos ante una creciente desigualdad económica y social global. La novedad es que esta creciente desigualdad se observa ahora también en el mismo seno de los países del norte, como es el caso de Estados Unidos (Stiglitz, 2012). La reacción de este país a esta coyuntura de crisis económica que estalló en 2008, y que perdura hasta hoy, era previsible ya que ha sido una constante en la historia de sus crisis económicas. ¡El culpable es el extranjero!

En lo que toca a nosotros, según Trump, nos hemos apoderado de los empleos industriales otrora bien remunerados, y somos criminales culpables de la creciente inseguridad en su país. No importa reconocer que las diferencias norte-sur prevalezcan como un rasgo consustancial al sistema capitalista, condición determinante del proceso de migración histórica México-Estados Unidos que ha contribuido a mejorar la calidad de vida de los estadounidenses. No importa que, acorde al régimen de producción posfordista, la acumulación de capital de muchas de las industrias trasnacionales estadounidenses se incremente gracias al traslado de procesos de producción intensivos en mano de obra a México, tal y como ha ocurrido en las ciudades de la frontera norte de México desde hace 50 años. No importa tampoco que los Estados Unidos sea el principal consumidor de drogas en el mundo.

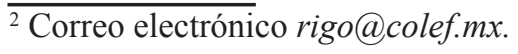


Ante el fracaso del capitalismo neoliberal, impulsado por cierto por los Estados Unidos desde mediados de la década de 1970 (Varoufakis, 2012), el presidente Trump pugna por una suerte de nacionalismo neoproteccionista. Su retórica es buy American, hire American.

El escenario que acabo de describir preocupa a la mayoría de las personas que vivimos en la frontera norte de México, región que no podría entenderse y explicarse sin su contraparte estadounidense. Compartimos una frontera de 3,152 kilómetros en la cual se ubican 38 municipios mexicanos y 25 condados estadounidenses, 14 pares de ciudades y 25 cruces internacionales. Con aproximadamente 91 millones de personas que viven ven los diez estados transfronterizos, esta región representa la cuarta economía mundial, sólo detrás de Estados Unidos, China y Japón (SEDATU, 2015; 13). Ante esta realidad, la preocupación subyace en el hecho de que desconocemos cómo afectará a esta región la nueva política económica y migratoria de Estados Unidos que anuncia el advenimiento de un nuevo orden mundial. Creo que la cuestión clave es reflexionar, de manera autocrítica, qué debemos hacer nosotros para enfrentarnos a esta realidad. En este sentido propongo, como marco explicativo de esta realidad, las nociones filosóficas de dos corrientes aparentemente dicotómicas: biopolítica y psicopolitica.

La biopolítica es propuesta originalmente por Michael Foucault como una relación entre política y vida, es decir, el poder sobre la vida. El cuerpo humano es un ente biopolítico que hay que educar y disciplinar para aumentar su productividad (Foucault, 1990). Roberto Esposito 3 advierte que la visión foucaultiana, si bien relevante en el sentido que reconoce esta forma de dominación inherente a las estructuras de poder de la etapa modernista, no logra explicar la realidad neoliberal, ya que no pudo llenar el vacío semántico entre bios y política. Espósito propone llenar este vacío a través de dos conceptos que, desde mi perspectiva, resultan clave para comprender el tema de las comunidades transfronterizas en la coyuntura política actual: comunidad e inmunidad.

Esposito deconstruye el concepto comunidad y encuentra que, contrario a la creencia de pensarla en términos de una pertenencia colectiva del individuo -visión eminentemente individualista-, comunidad es aquello que proyecta al individuo "...hacia afuera de sí mismo, de forma que lo expone al contacto, e incluso al contagio, con el otro" (Espósito, 2012; cap 1, párrafo 9). Comunidad es entonces, de acuerdo a su significado original, aquello que proyecta al individuo fuera de sí mismo para estar en relación (contacto) con la otredad, desarrollando así una voluntad de darse a los demás. Inmunidad, por el contrario, es la voluntad de construir o reconstruir barreras para evitar el contacto con elementos extraños. En el ámbito de la medicina, un cuerpo es inmune cuando resiste las infecciones que pueden desembocar en una enfermedad. Lo anecdótico es que lo que hace inmune al cuerpo es la aplicación de una proporción controlada de dicha enfermedad. Esta

${ }^{3}$ Roberto Espósito es, junto Giorgio Agamben, uno de los principales representantes de esta línea filosófica denominada biopolítica. 
analogía con la medicina remite a reconocer, en el campo de la biopolítica, que la inmunización en ciertas dosis es necesaria. Sin embargo, el exceso de inmunización conlleva inexorablemente a una negación de la vida misma, a una reclusión que atenta contra la libertad. Aquello que salva la vida puede, en determinadas circunstancias, causar la muerte.

Al pensar lo común con una lógica individualista, lo cual observamos claramente en la actualidad, cayendo incluso en un fundamentalismo del yo, en realidad segregamos y excluimos la diferencia y la otredad. Es decir, nos inmunizamos. Justo así es como funcionan los mecanismos de control implementados por las estructuras del poder capitalista neoliberal. Este poder no busca una relación comunitaria global. Al contrario, preserva las diferencias y desigualdades. Llama la atención que, a pesar de estar colmados hoy de toda clase de derechos humanos, somos testigos de que estos derechos no se respetan, evidencia empírica contundente del abuso por parte de aquellos que detentan el poder. La inoperancia de los derechos humanos, apunta Esposito, no es la falta de consideración o importancia que le damos al individuo. El problema radica en que no trascendemos esta visión individualista.

Byung - Chul Han, exponente emblemático de la psicopolítica, señala por el contrario que la biopolítica es inoperante en la era neoliberal. El cuerpo pierde relevancia como fuerza productiva, por lo cual la inmunización es irrelevante. "Para incrementar la productividad, no se superan resistencias corporales, sino que se optimizan procesos psíquicos y mentales" (Han, 2014, Capítulo 5, Párrafo 6). Gilles Deleuze había desarrollado previamente esta idea cuando señalaba que la competitividad deriva en una rivalidad perpetua entre las personas que vuelve inoperante los controles externos, ya que son ellos mismos los que lo ejercen y aplican (Deleuze, 1999). Aquí radica precisamente la esencia seductora del capitalismo neoliberal. No impone, no restringe, no se apodera de nosotros. Explota la psique para que nosotros nos autoexplotemos. Nos volvemos consumistas insaciables ${ }^{4}$ en un entorno de completa libertad donde nos comunicamos, socializamos y compartimos nuestras ideas, sentimientos y emociones que nos hacen crear nuevas necesidades. El Facebook se ha convertido en el templo donde se congrega la comunidad global, y el "like" es el Amén de hoy (Han, 2014). Pero esta libertad es aparente ya que ella misma nos coacciona por medio de la ilusión del poder ilimitado. "El deber tiene un límite. El poder hacer, por el contrario, no tiene ninguno (Han, 2014).

Volviendo al campo de la medicina, Byung-Chul Han piensa que la inmunización es un concepto casi inoperante en el siglo XXI. Las enfermedades de hoy son mentales, neuronales. A diferencia de las enfermedades bacteriales y virales que explotaron en los dos siglos anteriores, en el mundo entero se expanden hoy en día el estrés y la depresión. En el paradigma biopolítico, la

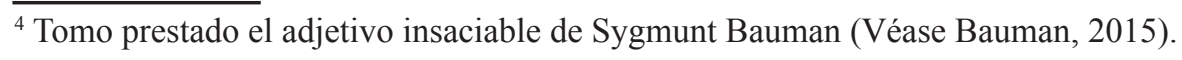


inmunología se sustenta con base en la otredad, es decir, se reacciona contra lo extraño. En la etapa neoliberal, por el contrario, "comparece la diferencia, que no produce ninguna reacción inmunológica" (Byung-Chul, 2012, Capítulo 2, Párrafo 3). Así, lo extraño desaparece y las enfermedades mentales surgen por una violencia no a lo extraño o diferente, sino a lo similar o incluso a lo idéntico.

Resulta interesante llevar estas nociones de filosofía política a las comunidades transfronterizas, ya que representan un laboratorio social donde podemos observar las relaciones entre sociedades de dos mundos diferentes. Estas relaciones presentan, desde mi perspectiva, una tensión constante entre comunidad e inmunidad, entre control físico y control mental, entre biopolítica y psicopolítica. Los que vivimos en el lado mexicano convivimos con nuestros vecinos fronterizos y defendemos la idea de lo valioso que es vivir en comunidad. Muchos estadounidenses piensan lo mismo, pero muchos otros defienden la necesidad de inmunizarse para evitar el contagio social mexicano o latinoamericano.

Con el Tratado de Libre Comercio de América del Norte (TLCAN) que entró en operación en 1994, parecíamos entrar en una nueva era que fortalecería los lazos comunitarios. Eliminar barreras comerciales y olvidar cualquier tentación proteccionista y sustitutiva de importaciones significaba abrirnos al mundo. Significaba que podíamos competir con cualquiera y alcanzar por fin el tan anhelado desarrollo económico y social, esto fincado en una mejor educación que nos permitiría ser más productivos y competitivos. Competitividad se convirtió desde entonces en una suerte de mantra omnipresente en la narrativa del poder. Sin embargo, en la frontera norte de México fuimos testigos de un escenario contradictorio. A pesar de esta intensificación en las relaciones comerciales, Estados Unidos inició justo en la década de 1990 la construcción de un muro fronterizo y reforzó los controles migratorios. De la misma manera, la guerra contra el narcotráfico iniciada en México en la primera década del siglo XXI, que en sí misma implica una inmunización al segregar la otredad ejemplificada en las personas que usan drogas, ${ }^{5}$ derivó en una masacre que reforzó la necesidad de recluirnos cada vez más en nosotros mismos y evitar el contacto y la relación con los demás. Nos convertimos desde entonces -o quizás nunca lo dejamos de ser- en comunidades transfronterizas inmunizadas.

Vivimos una aporía. Vivimos con incertidumbres. ¿Qué hacer? Concluyo lo siguiente. En primer lugar, creo que el entorno global actual nos muestra que no podemos separar cuerpo y psique. Es verdad que proliferan las enfermedades mentales como el estrés y la depresión, pero esto no impide que puedan aparecer enfermedades virales y bacteriales, o incluso que se dañe físicamente el cuerpo para eliminarlo, para matarlo. ${ }^{6}$ La ilusión de un desarrollo basado en la competitividad perpetua condujo, en realidad, a una doble violencia. Violencia hacia lo idéntico y violencia hacia

\footnotetext{
${ }^{5} \mathrm{Y}$ que obviamente es, desde mi perspectiva, un mecanismo de acumulación de capital implementado por el poder.
} 
lo extraño. Por un lado, nos autoexplotamos nosotros mismos e implementamos mecanismos de control con una lógica individualista, sin darnos cuenta que con esto fuimos parte del engranaje neoliberal global que condujo a una mayor desigualdad económica y social. Por el otro, la política de Trump evidencia una estrategia de inmunización que nos segrega y nos advierte que, aunque vivimos en el norte, seguimos perteneciendo al sur.

Ante este escenario, considero que los daños corporales son necesarios para imponer ciertos límites a la psique. Con esto quiero decir que, para mí, la llegada de Trump a la presidencia de Estados Unidos es una gran oportunidad para que los vivamos en la frontera norte, y en general todos los mexicanos, pensemos que el desarrollo puede lograrse con una lógica más comunitaria que individualista, es decir, que hay estilos de desarrollo diferentes a la lógica occidental. Para esto, debemos aprovechar el poder de comunicación que nos ofrecen las tecnologías de la información y, en general, aprovechar los aspectos positivos que existen en el mundo global de hoy para que alcancemos un desarrollo económico y social más equitativo. Debemos abrirnos al mundo con la dosis mínimamente necesaria de inmunización ya que, de lo contrario, correríamos el riesgo de colapsar como país. Aprovechemos la inversión extranjera, pero desarrollemos estrategias de desarrollo alternativas, como un mayor impulso al mercado interno que revierta las consecuencias negativas que trajo el neoliberalismo a muchas de las industrias nacionales y, sobre todo, al campo mexicano. Desarrollemos un modelo educativo que sea realmente integral, que nos brinde las herramientas necesarias para que nos proyectemos hacia afuera y nos expongamos al contacto con culturas y estilos de vida diferentes. Creo que sólo de esta manera podremos convivir dignamente en nuestras comunidades transfronterizas inmunizadas.

\section{Referencias bibliográficas y documentales}

Bauman, Z. (2015). Modernidad líquida. México, Fondo de Cultura Económica.

Deleuze, G. (1991). "Posdata sobre las sociedades de control”, en El lenguaje literario, Cristian Ferrer (Comp.), T 2, Ed. Nordan, Montevideo, Traducción: Martín Caparros.

Espósito, R. (2012). Comunidad, inmunidad y biopolítica. Barcelona: Herder

Foucault, M. (1990). Vigilar y castigar: nacimiento de la prisión, Siglo XXI.

Han, Byung-Chul (2012). La sociedad del cansancio, Herder.

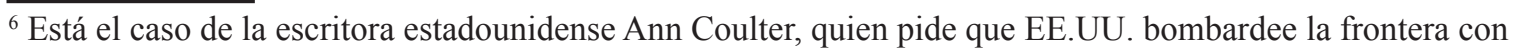
México para eliminar la migración (Véase https://www.youtube.com/watch? $\mathrm{v}=\mathrm{j} 1 \mathrm{xB} 0 \mathrm{OwB} 3 \mathrm{Y}$ ) 


\section{- 3. Las relaciones internacionales y la Frontera México-Estados Unidos en la era de Donald Trump.}

Sergio Peña Medina ${ }^{7}$

El objetivo de este breve ensayo es hacer un análisis prospectivo e identificar posibles escenarios que se avecinan con respecto a las relaciones México-Estados Unidos y su impacto en la frontera que ambos países comparten. El ensayo se divide en dos partes: una primera parte es llevar a cabo un marco analítico que nos permite guiar el análisis; una segunda parte, es identificar los escenarios y las probabilidades que cada uno de los escenarios tiene.

\subsection{Las relaciones internacionales y las fronteras: un marco analítico.}

A grandes rasgos existen dos paradigmas que sirven como marcos referenciales para explicar las relaciones internacionales que existen entre los Estados-nación. Por un lado existe el paradigma denominado clásico o neorrealista y por otro lado el denominado transnacionalista. El objeto central de las relaciones internacionales es lograr que el sistema mundial logre una estabilidad que dé como resultado paz y prosperidad ante la falta de un "leviatán mundial." Es decir, ante la falta de un órgano de gobierno mundial que aplique sanciones a quienes violan las normas internacionales los países garantizan la estabilidad ya sea por medio de un Estado-Nación hegemónico (ej. Estados Unidos) que se adjudica la función de policía del orden mundial o la creación de un organismo multilateral que asuma el rol de mediador.

El paradigma neo-realista parte del supuesto que los Estados-nación son agentes racionales que tienen como meta maximizar su utilidad/interés de manera egoísta; las relaciones o acuerdos que se negocian son de índole bilaterales donde cada Estado negocia con aquel con quien tiene un interés en hacerlo; los acuerdos bilaterales son de índole instrumental; es decir, los acuerdos y el poder son un medio que cada Estado tiene para lograr un fin. El paradigma transnacionalista parte de la idea que la cooperación y los acuerdos multilaterales son un medio para lograr prosperidad y paz. El meollo del asunto en el transancionalismo es desarrollar una arquitectura institucional transnacional o un "leviatán mundial" que de gobernabilidad al sistema mundial. El sistema transnacional basado en organizaciones transnacionales tiene como objetivo central el producir bienes globales (ej. Seguridad, protección del ambiente, entre otros) que afectan a todo el planeta o región y que un acuerdo bilateral no sería el instrumento adecuado.

\footnotetext{
${ }^{7}$ Correo electrónico: spena@colef.mx.
} 
Según el historiador paseño Oscar Martinez (1998), las fronteras atraviesan por cuatro etapas o estadios: una primera etapa es la de alienación dado que las fronteras son el resultado de conflictos entre naciones, una segunda etapa de coexistencia pacífica, posteriormente una etapa de cooperación y finalmente la etapa de integración. Por su parte Ansi Paasi (2011) argumenta que las fronteras son socialmente construidas a traviesan por un proceso de cuatro etapas: 1) una etapa que da forma territorial a la frontera, 2) una etapa de formación simbólica que sirve para clasificar y/o diferenciar, 3) una etapa de institucionalización de procesos cooperativos, y 4) una etapa donde se forma una identidad regional.

\section{2. ¿Dónde estamos y hacía dónde nos dirigimos?}

Podríamos argumentar que la era denominada del TLCAN es un proceso donde las relaciones internacionales en América del Norte en cierta medida se aproximaban al modelo transnacionalista de crear una región prospera basada en el libre flujo de mercancías, y además de crear las instituciones que dieran una gobernabilidad al tema de los bienes públicos transnacionales como son el medio ambiente. Similarmente, se trataba de producir una cooperación para abordar los "males" públicos o la economía ilícita (Andreas, 2004) que se desarrollaba de manera paralela como el narcotráfico y el tráfico de personas. La frontera México-Estados unidos por su parte, usando el marco analítico de Martinez (1998) y Paasi (2011), experimentó un proceso de institucionalización para abordar problemas transfronterizos relacionados con las externalidades negativas producto de la integración económica, además de empezar a formar una identidad regional.

Los atentados terroristas del 11 de septiembre del 2001 y la elección de Donald Trump en el 2016 marcan una etapa de transición y redefinición de la frontera. El futuro de la relación México- Estados Unidos y la frontera fueron el tema de deliberación en la política de ambos países, pero particularmente en los Estados Unidos. Candidatos como Ross Perot en 1992 denomino la relación como una "sonido de succión gigantesco" (giant sucking sound) para referirse al TLCAN ante la amenaza de la pérdida de empleos en Estados Unidos; mientras que por su parte Pat Buchanan jugó la carta racista anti-inmigrante. Las administraciones tanto de demócratas (Bill Clinton y Barack Obama) como republicanos (George W. Bush) coincidieron en reforzar la frontera y continuar con la construcción del muro. Donald Trump logró triunfar con la retórica anti libre comercio, anti-México y con la promesa de hacer el muro fronterizo mucho más visible.

En resumen, podríamos decir que la relación México-Estados Unidos en la era Trump se encamina a retomar la noción neorrealista del mundo, y con ello la frontera, con base en Paasi (2011), vuelve a tener una connotación de formación territorial y de formación simbólica que sirve para diferenciar a los que forman parte y aquellos que no y que tienen que ser expulsados y excluidos. El interés del Estado-Nación predomina sobre cualquier otro por lo tanto la retórica de Trump de "America Primero." 


\subsection{Futuros escenarios de la relación México-Estados Unidos.}

El escenario menos probable y del día del juicio final. En este escenario Donald Trump tiene éxito en avanzar su agenda radical de extrema derecha un nacionalismo excluyente al ser re-elegido hasta el año 2024. Aquí el TLCAN deja de existir y Estados Unidos renuncia a la Organización Mundial de Comercio $(\mathrm{OMC})$ desatando una guerra comercial, la frontera se convierte en el símbolo de diferenciación y la cooperación casi es inexistente. El triunfo del neorrealismo y la frontera como demarcación territorial de soberanía del Estado.

El escenario con mayor probabilidad. La democracia prevalece en Estados Unidos y los contrapesos funcionan. Esto parte del supuesto que la democracia es una póliza de seguro a los riesgos de políticas extremas. En este escenario la administración Trump se enfrenta a la opinión pública que lo resiste y lo confronta; los medios de comunicación continúan haciendo público conflictos de interés y la relación de Rusia deslegitima su presidencia. Las elecciones intermedias le pagan factura y los demócratas se vuelven mayoría en el Senado. La agenda de Trump es más difícil de implementarse. El muro fronterizo enfrenta serios cuestionamientos por el costo que éste representa, y la prospectiva de que se pague por medio de un impuesto fronterizo, por los altos riesgos que esto implica ante la respuesta de México de incrementar aranceles. El TLCAN se modifica solamente de manera marginal. En resumen, un transnacionalimo light y una frontera siempre en una dinámica dialéctica, entre la apertura a bienes y personas documentadas, y cada vez menos accesible a los flujos indocumentados de personas.

En conclusión, el escenario más probable no significa que es una realidad futura y que debemos ser complacientes. México, independientemente del escenario que se desenlace, tiene que hacer su tarea en dos niveles: externo e interno para disminuir su vulnerabilidad y estar en una mejor posición vis a vis los Estados Unidos. A nivel externo, México debe de dejar de victimizarse y adoptar una postura más pragmática basada en conceder para recibir, respetando principios básicos basados en un concepto de soberanía más funcional y menos ideológico; un cabildeo más efectivo que logre llegar a los oídos de los tomadores de decisiones en los congreso y senados de los Estados Unidos y de aquellos donde hay un fuerte vínculo comercial. Una soberanía más funcional significa un enfoque de "esto por aquello"; es decir, México necesita definir sus prioridades o lo que quiere lograr de las relaciones con los Estados Unidos y negociar sus prioridades reconociendo que tendrá que llevar a cabo acciones o políticas que lo obligaran a ceder en algunas áreas. Un ejemplo, es el acuerdo entre Canadá y Estados Unidos donde los agentes de migración de Estados Unidos operan en los aeropuertos de Canadá para autorizar a los pasajeros y éstos al llegar a Estados Unidos ya no tiene que pasar por migración ¿México estaría dispuesto a permitir algo parecido sin argumentar que la soberanía se ha violado?

Además, La gran tarea sigue siendo como hacer que la democracia produzca valor público. Los 
temas a resolver son, el combate a la corrupción, la diversificación de la economía para hacerla menos dependiente del mercado de Estados Unidos, la consolidación del Estado de derecho, el respeto a los derechos humanos tanto de los nacionales como de los inmigrantes centroamericanos y haitianos que cruzan o que se quedan en el país; entre otros temas.

\section{Referencias bibliográficas y documentales}

Andreas, Peter. (2004). "Illicit international political economy: the clandestine side of globalization", en Review of International Political Economy. 11(3), 641-652.

Martínez, Oscar. (1998). Border People: Life and Society in the U.S.-Mexico Borderlands. Tucson, AZ: The University of Arizona Press.

Paasi, Anssi. (2011). The region, identity, and power. Procedia Social and Behavioral Sciences, 14, 9-16. 


\section{$\rightarrow$ 4. Posibles escenarios de seguridad fronteriza a partir de la propuesta de Donald Trump de construir un muro fronterizo.}

César Mario Fuentes Flores ${ }^{8}$

Desde la campaña política de Donald Trump y a partir de su toma de posesión como presidente de Estados Unidos centró su discurso en el tema de la recuperación la frontera sur. En los primeros días de su mandato firmo la acción ejecutiva sobre seguridad fronteriza que en su inciso c señala que "se busca garantizar la seguridad de la frontera sur de Estados Unidos a través de la inmediata construcción física de un muro en la frontera sur supervisado y apoyado por personal adecuado a fin de impedir la inmigración ilegal, el tráfico de drogas y de seres humanos y los actos de terrorismo" (Acción ejecutiva, 2017).

En este sentido, la acción ejecutiva busca continuar con el enfoque prohibicionista que ha tenido la política antidrogas de Estados Unidos, pero ahora tomado una posición radical al buscar cerrar los espacios para el flujo de drogas en la frontera entre México y Estados Unidos.

La política seguida por Estados Unidos en materia de drogas ha tenido como estrategia la erradicación de cultivos, interdicción de los cargamentos y la encarcelación de los narcotraficantes, consumidores, vendedores etc. (Martin, 2013). En este contexto, las acciones se centraron en detener los flujos de las drogas durante su tránsito, en específico puso mayor énfasis en las políticas de interdicción de los países productores y de tránsito. Es por ello que éstas se centraron en especial la frontera norte a ser un espacio de tránsito ideal para la interdicción de drogas prohibidas.

En 1969 la administración del expresidente Nixon implementó la Operación Intercepción que consistió en revisiones exhaustiva para identificar y confiscar droga en la frontera norte de México. Posteriormente se implementó el programa Operación Cooperación que ambos países coordinados y de manera conjunta implementaban controles fronterizos. Dichos programas se endurecieron a partir del 2001 como resultado de los ataques terroristas a las Torres Gemelas de Nueva York lo que condujo al reforzamiento de la seguridad en las fronteras por parte de las agencias de seguridad del gobierno de Estados Unidos. A partir de esa fecha la prioridad para Estados Unidos ha sido la seguridad nacional con los consecuentes impactos negativos en la relación transfronteriza. Por lo anterior, para no afectar los flujos de la economía legal en el año 2002 se implementó el Programa Fronteras Inteligentes, bajo el cual se formalizó la cooperación antiterrorismo entre los dos países y se consolidó la participación de todo el sistema de seguridad nacional mexicano (Correa, 2014). Dicho programa tenía como uno de sus objetivos facilitar el flujo de las economías legales a través de las fronteras entre México y Estados Unidos. En el 2001 se firmó el Plan de Ac-

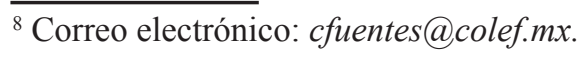


ción para la Seguridad de la Frontera el cual se ratificó y amplió en el Plan de Seguridad Fronteriza que se signó en 2004 (Benítez y Rodríguez, 2006). Los principales puntos del plan se centraban en facilitar el intercambio de información para combatir las organizaciones del tráfico de personas y ampliar los programas de capacitación e intercambio de conocimientos entre las autoridades encargadas de aplicar el plan (Creel, 2004; 11 citado por Benítez y Rodríguez, 2006). En el 2005 se firmó la Alianza Para la Seguridad y Prosperidad de América del Norte (ASPAN) que permitió avanzar en la generación de proyectos de inversión en comunidades del centro del país (Benítez y Rodríguez, 2006).

A partir del 2008 se acordó la Iniciativa Mérida entre los gobiernos de ambos países con el objetivo de apoyar la lucha en contra del crimen organizado transnacional por parte del gobierno de México, la cual se centró en la compra de equipo militar, entrenamiento y asistencia técnica. El presidente Obama amplió la Iniciativa Mérida y la llamó más allá de la Iniciativa Mérida, la que tomó forma con los llamados cuatro pilares. El tercer pilar se centró en construir la Frontera del Siglo XXI, con el reto de prevenir el flujo de bienes ilícitos e individuos catalogados como peligrosos y permitir que el comercio y los viajes ocurran de manera libre. Si bien es cierto que la Iniciativa Mérida tuvo algunos logros ésta sigue siendo más del enfoque prohibicionista que ha permeado el diseño de las políticas antidrogas de Estados Unidos y además contribuyó a una creciente militarización de la región fronteriza y de México en su conjunto.

En la recién estrenada administración presidencial de Donald Trump aunque no se conoce a detalle su propuesta de seguridad fronteriza ésta se ha centrado en la construcción del muro fronterizo. En su discurso ante el Senado de Estados Unidos presentó algunos esbozos de la política que seguirá su gobierno en el tema de la seguridad fronteriza la que se centra en la construcción del muro en la frontera entre ambos países con el objetivo de detener los flujos de drogas prohibidas, migrantes no autorizados y potenciales terroristas para mejorar la seguridad de su frontera sur. Lo anterior, es una clara señal que su propuesta busca endurecer aún más la política prohibicionista que se han seguido las anteriores administraciones presidenciales de Estados Unidos y sellar aún más las fronteras a los flujos antes mencionados.

Sin embargo, la política prohibicionista seguida por Estados Unidos e impuesta a muchos otros países del mundo entre ellos a México ha sido un fracaso, ya que, a pesar del endurecimiento de la vigilancia en la frontera sur de Estados Unidos con un mayor número de agentes de la Patrulla Fronteriza, el bloqueo físico con una barda en algunas zonas de la frontera y el bloqueo virtual mediante el uso de drones, aviones no tripulados, radares, etcétera, no se observa una baja considerable de los flujos de drogas prohibidas. En el cuadro 1 se muestra una estabilización de los volúmenes de drogas como marihuana, cocaína que se decomisan en los puertos de entrada entre México y Estados Unidos durante el periodo 2005-2011. 
El impacto de la política prohibicionista se puede analizar por tipo de droga, por ejemplo, las drogas de grande volumen como la marihuana condujo a que los grupos del crimen organizado transnacional buscaran otros mecanismos para su cruce más allá de los puertos internacionales, tales como túneles, catapultas, puentes colgantes, vehículos, personas, etcétera. Por ello la respuesta del gobierno de Estados Unidos fue la contratación de más agentes de la Patrulla Fronteriza y otras agencias de seguridad lo que contribuyó a que el crimen organizado transnacional volviera a usar otras estrategias entre los que se incluyen los puertos fronterizos. De acuerdo con la Agencia de Seguridad Interna de Estados Unidos del 2011 al 2016 se redujo el número de túneles encontrados a lo largo de la frontera sur de Estados Unidos al pasar de 18 en 2011 a 9 en el 2016.

Por otra parte, las únicas drogas en las que se incrementaron los decomisos en el periodo fueron la heroína y las metanfetaminas. De acuerdo con la DEA el método más común de contrabando de este tipo de drogas prohibidas es a través de los puertos fronterizos (DEA, 2016). Por lo anterior, tanto en los casos del flujo de marihuana, como en el de heroína y metanfetaminas, la construcción de un muro con el objetivo de detener el cruce de las drogas prohibidas tendría poco efecto en evitar su paso.

Cuadro 1

Peso de drogas ilegales decomisadas en puertos fronterizos entre México y Estados Unidos (2005-2011) (toneladas)

\begin{tabular}{|c|c|c|c|c|c|c|}
\hline Año & Marihuana & Cocaína & Heroína & Metanfetaminas & Otras* & Total \\
\hline 2005 & 217.7 & 11 & 1.6 & 1.4 & 0.6 & 232.3 \\
\hline 2006 & 203.3 & 12.8 & 0.3 & 1.6 & 0.4 & 218.4 \\
\hline 2007 & 255.0 & 10.8 & 0.3 & 0.9 & 0.2 & 267.2 \\
\hline 2008 & 249.9 & 8.2 & 0.5 & 1.1 & 0.2 & 259.9 \\
\hline 2009 & 263.1 & 8.6 & 0.5 & 2.3 & 0.4 & 274.9 \\
\hline 2010 & 236.8 & 11.1 & 0.7 & 2.9 & 0.7 & 252.2 \\
\hline 2011 & 253.6 & 10.8 & 1.0 & 4.2 & 0.9 & 270.5 \\
\hline Total & 1679.4 & 73.1 & 3.3 & 17.1 & 3.3 & \\
\hline
\end{tabular}

Fuente: Elaboración propia con base en información del Departamento de Protección Fronteriza y Aduanas de Estados Unidos (2012). 
Los posibles efectos pueden tener varios escenarios potenciales. El primero escenario es que a pesar de la existencia del muro los flujos de continúen cruzando la frontera como ha ocurrido hasta ahora a pesar del incremento en el número de agentes de la Patrulla Fronteriza, ICE, de la instalación de radares, uso de helicópteros, drones, aviones no tripulados, etc., el crimen organizado transnacional continúa cruzando drogas de muy diversas maneras y mediante distintos mecanismos entre los que se incluyen túneles, puentes artificiales, vehículos de carga, vehículos particulares, catapultas, peatones, estudiantes, la colaboración de algunos miembros de agencias de seguridad fronteriza de Estados Unido, etc. Lo anterior, ha demostrado que el crimen organizado transnacional se encuentra en constante innovación para hacer frente al cierre de la frontera a los flujos ilícitos.

El segundo escenario es que el muro realmente si cerrara el paso de los flujos de drogas prohibidas, los potenciales efectos serían diferenciados por tipo de droga. En el caso de la marihuana su siembra, empaque, distribución y comercialización se podría trasladar a los estados de Estados Unidos en donde todavía no es legal para usos medicinales y recreativos. Es importante, mencionar que los cárteles también verían afectadas sus ganancias debido a que varios estados en Estados Unidos legalizaron el uso de la marihuana para propósitos medicinales y recreativos por lo que los consumidores no tienen que recurrir al mercado negro para su compra. Algo similar ocurriría con las drogas sintéticas como las metanfetaminas las que al sellarse la frontera se podrían producir en laboratorios en Estados Unidos. Lo que sí tendría que cruzar de manera clandestina son los ingredientes como la pseudoefedrina, etc. Lo anterior, tendría como resultado de que al haber menor oferta el precio aumentará y haría más atractivo el negocio y surgirán un mayor número de productores. Lo cual potencialmente podría conducir a un incremento de la violencia entre grupos del crimen organizado por una mayor competencia por los mercados de consumo.

En el caso de drogas como la cocaína que solo se produce en Sudamérica podría buscar una nueva ruta como ya ocurrió cuando se trasportaba a través del océano Atlántico y una vez que la ruta fue cerrada por las agencias de seguridad de Estados Unidos se buscaron nuevas rutas como fue el caso de la frontera norte de México. Del flujo que continúe seguir pasando por la frontera norte no lo podrá hacer de manera rápida por lo que las organizaciones criminales posiblemente buscarán almacenar sus cargamentos en las ciudades de la frontera norte antes de cruzarla. Lo mismo ocurriría en las ciudades fronterizas de Estados Unidos que también tienen la función de almacenamiento antes de distribuirse al resto de Estados Unidos. Por lo que lo anterior, podría incrementar los niveles de violencia en ambos lados de la frontera entre México y Estados Unidos por la disputa entre cárteles por el control de rutas, cruces fronterizos en donde la frontera es menos vigilada y es más fácil el cruce. Lo anterior, contradice el planteamiento de Donald Trump de buscar construir el muro para tomar control de la frontera sur de Estados Unidos. Otro potencial 
impacto negativo para México y las ciudades fronterizas sería que al no poder pasar el flujo de drogas, los cargamentos se queden en las ciudades fronterizas y busquen consumidores locales, con el consecuente aumento de adicciones en los principales municipios fronterizos mexicanos (Ramos, 2011). Para lo cual se tendrían que fortalecer las políticas de prevención y tratamiento antidrogas, como opciones para reducir su consumo en México y Estados Unidos.

De igual manera el costo de drogas como la cocaína podría incrementarse al aumentar los riesgos para su cruce al mercado de Estados Unidos. De acuerdo con fuentes de información de inteligencia las ganancias del trasiego de drogas ilegales son tan grandes que por ejemplo, los cárteles mexicanos compran en Colombia el kilo de cocaína en $\$ 2,000$ dólares, cuando llega a la frontera norte de México ese kilo ya vale $\$ 30,000$ dólares y una vez que cruza la frontera y es colocada en mercados finales como el de Nueva York se llega a cotizar en \$100,000 dólares (Business Insider, 2015).

Un tercer escenario potencial es el efecto diferenciados por regiones a lo largo de los 3,124.3 kilómetros de la frontera norte, ya que los flujos de drogas como la marihuana, cocaína, heroína y metanfetaminas ya tienen rutas de transporte bien definidas. Por ejemplo, tanto la marihuana como la cocaína siguen principalmente la ruta de cruce por los puertos de Sonora y Arizona para llegar al mercado de las ciudades del Oeste de Estados Unidos en donde vive población de mayores ingresos. Lo mismo ocurre con las rutas que cruzan entre Tamaulipas y Texas para llegar a las grandes ciudades del Este de Estados Unidos. La construcción del muro implicaría una reorganización de las rutas y cruces de drogas lo que potencialmente signifique el enfrentamiento de los grupos delictivos que controlan esos cruces con los que busquen también usar dichas rutas cuando se cierren las que actualmente usan.

Un cuarto escenario potencial sería que se buscaran rutas marítimas y se abandonaran las terrestres. Un proceso opuesto al que sucedió con el establecimiento del Plan Colombia que indujo a que los cárteles colombianos cambiaran sus rutas de transporte del Atlántico a las de la frontera terrestre de México con Estados Unidos. De acuerdo con información del gobierno de Estados Unidos en los últimos 5 años se incrementó el número de embarcaciones detenidas con drogas en las costas de Estados Unidos.

Finalmente, un último potencial escenario es que Estados Unidos reduzca la demanda de drogas mediante de política pública que combine el enfoque prohibicionista y el de salud pública que busque fortalecer las políticas de prevención y tratamiento antidrogas, como opciones para reducir el consumo. Lo cual significaría una reducción en la demanda y por consecuencia en la reducción de las ganancias y el atractivo para el crimen organizado transnacional.

En términos de política pública el problema del tráfico de drogas prohibidas no debe ser abordado desde un enfoque nacional como lo plantea Donal Trump, sino que debe ser integrado desde un 
enfoque multinacional en la que deben participar todos los países que integran la cadena desde productores, transportadores, comercializadores y consumidores. En la que cada uno de ellos implemente acciones para reducir los flujos, especialmente los países consumidores deben buscar reducir la demanda de este tipo de sustancias al buscar implementar acciones que no busquen criminalizar a los consumidores sino mediante la implantación de un enfoque de salud pública a través de programas de rehabilitación se reduzca el consumo.

\section{Referencias bibliográficas y documentales}

Benítez Manaut, Raúl y Carlos Rodríguez Ulloa, 2006, "Seguridad y fronteras en Norteamérica: del TLCAN a la ASPAN”, en Frontera Norte, vol. 18, núm.35, pp. 7-28.

Correa, Guadalupe, 2014, "Seguridad y migración en las fronteras de México: diagnóstico y recomendaciones de política y cooperación regional”, en Migración y Desarrollo, vol. 12, núm. 22, pp. 147-171.

Creel, Santiago, 2004, "La migración y la seguridad entre México y Estados Unidos", en Foreign Affairs en Español, vol. 4, núm.2, pp. 23-33.

DEA, 2016, "Evaluación de la Amenaza de las Drogas 2016," DEA. Martin, William, 2013, “Cartels, Corruption, Carnage, and Cooperation", en A War That Can't Be Won, Tony Payán, Kathleen Staudt y Antonio Kruszewski, (eds.), University of Arizona Press, Estados Unidos, pp. 33-62.

Ramos, José María, 2011, “Gestión de la seguridad en la frontera norte e Iniciativa Mérida: antecedentes y desafíos”, en Migración y seguridad: nuevo desafio en México, Natalia Armijo (ed.), México. 


\title{
- 5. Realidad vs hechos alternativos: la migración irregular hacia Estados Unidos y las deportaciones de población mexicana en los inicios de la administración Trump.
}

\author{
Jesús Javier Peña Muñoz ${ }^{9}$
}

Las órdenes ejecutivas en materia de control migratorio firmadas por Donald Trump el 25 de enero indican que se piensa proseguir por medio de una doble estrategia. Por un lado, Trump firmó una orden ejecutiva enfocada a mejorar la seguridad en la frontera México-Estados Unidos (Executive Order: Border Security and Immigration Enforcement Improvements). Esta orden busca asegurar los recursos que se consideren necesarios para expandir la capacidad de detención de las autoridades migratorias que operan en la frontera. Se incluye, por supuesto, la construcción de manera inmediata de 1,250 millas de muro fronterizo, con un costo calculado en 21 billones de dólares y una fecha de conclusión en el 2020.Por otro lado, la otra orden ejecutiva firmada ese día está orientada a expandir las capacidades de control migratorio más allá de la frontera con México. Bajo el manto de cuestiones de seguridad pública, esta orden contiene provisiones para agilizar el proceso de detención y deportación de migrantes irregulares que han cometido algún tipo de ofensa sin importar su gravedad; incluye también delegar funciones de control migratorio a todas las agencias encargadas de la seguridad pública (Executive Order: Enhancing Public Safety in the Interior of the United States).

Esta estrategia de doble enfoque tiene sentido dentro de la narrativa que Trump impulsó durante su campaña y confirma lascreencias de muchos de sus seguidores: los inmigrantes indocumentados, las drogas, los criminales y los terroristas entran a nuestro país por la falta de límites fronterizos fuertes y por las políticas migratorias laxas. Esta postura está fundamentada en gran medida en información poco fundamentada en la realidad. El uso de información poco confiable e incluso la fabricación de datos se ha vuelto algo tan común en las decisiones que ha tomado la administración Trump que hasta su propio staff le ha dado un nombre a la información que manejan: "hechos alternativos". La situación en México no es tan diferente, mucho menos en la frontera norte, donde gobierno como sociedad por igual, buscan hacer frente a las órdenes ejecutivas de Trump desde la desinformación y la ignorancia sobre la situación actual de la migración mexicana hacia Estados Unidos.

En materia de migración, una de las principales incertidumbres para la frontera norte de México, que la doble estrategia de control migratorio impone, es el posible aumento en las deportaciones de población mexicana, las cuales se realizan en su mayoría por puntos en las principales ciudades de esta región. No obstante, antes de aventurarnos a hacer predicciones sobre escenarios

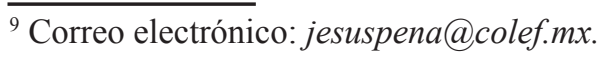


próximos, es fundamental conocer primero la realidad de los flujos migratorios de población mexicana hacia Estados Unidos. A continuación, se presentan cuatro hechos alternativos que impulsan la política migratoria de Trump y que informan la reacción del lado mexicano, y su contraparte con datos reales recabados de la United States Department of Homeland Security, el Instituto Nacional de Migración (INAMI) y la Encuesta sobre Migración en la Frontera Norte (EMIF Norte). Con base en el análisis de estos datos se proponen tres tesis: 1) no hay fundamentos en el estado actual de la migración mexicana hacia Estados que justifique el contenido de las órdenes ejecutivas de Trump, 2) el principal reto para los gobiernos y sociedades fronterizas en México con respecto a la deportación de la población mexicana no se encuentra en la cantidad de personas, sino en la diversidad de perfiles y necesidades de esta población y 3) las órdenes ejecutivas de Trump solamente tienen sentido si se les entienden como estrategias de control de la población orientada a inhibir el crecimiento de la población mexicana en Estados Unidos, en vez de acciones para el control de la migración irregular.

\subsection{Hecho alternativo: el cruce irregular hacia Estados Unidos de población mexicana es cada vez mayor. Realidad: el cruce irregular hacia Estados Unidos registra su nivel más bajo histórico.}

El monto de migrantes mexicanos que llega a la frontera norte de México con intenciones de cruzar de manera irregular hacia Estados Unidos es el más bajo desde 2003. Desde 2003, el único aumento de intentos de cruce tuvo lugar en 2007 (gráfica 1), justo antes del colapso del sistema financiero en Estados Unidos. En 2015, la EMIF Norte registró 41,184 desplazamientos de este tipo, cifra que representa 641,376 desplazamientos menos que en 2007. 
Gráfica 1

Flujo de migrantes procedentes del sur que buscarían ingresar a Estados Unidos sin documentos

2003-2015

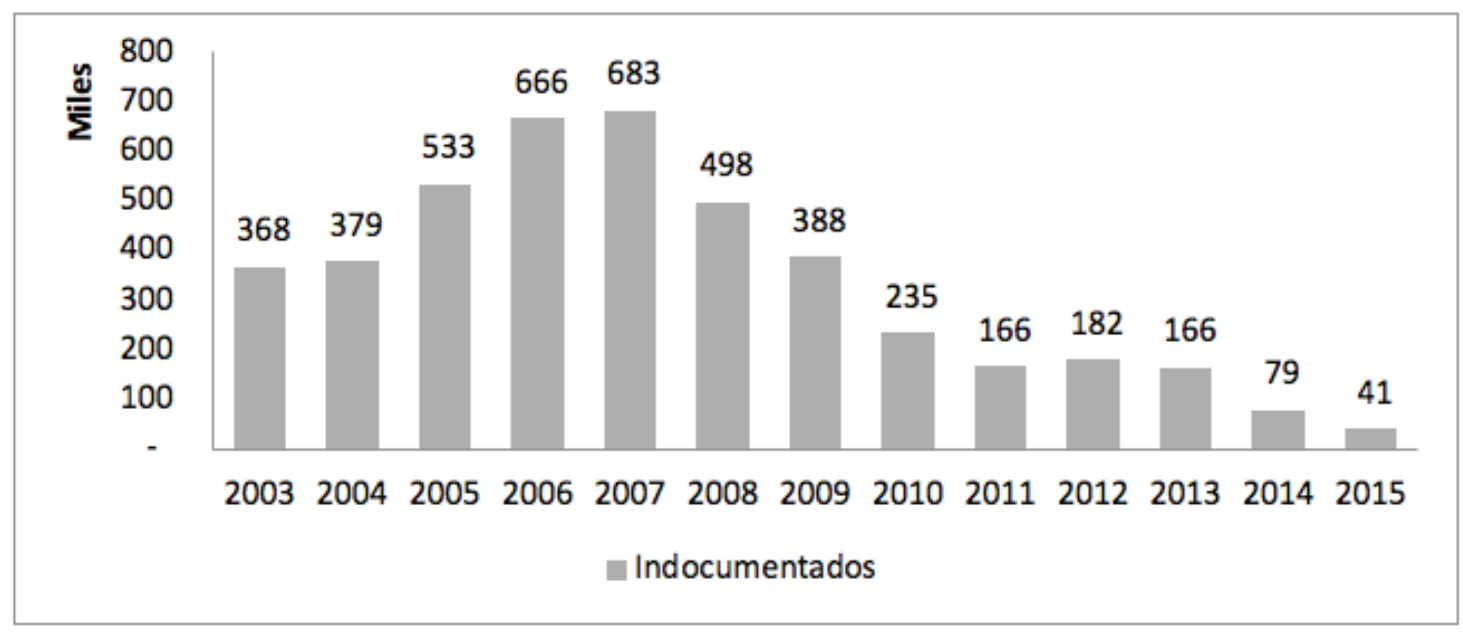

Fuente: Elaboración propia con base en la Emif Norte, 2003-2015.

5.2. Hecho alternativo: las políticas de control migratorio del gobierno estadounidense se han enfocado a detener la entrada a Estados Unidos de migrantes mexicanos irregulares procedentes de la frontera norte de México. Realidad: En años recientes, las políticas de control migratorio se han enfocado a detener y deportar población migrante establecida de manera permanente en Estados Unidos.

La creación en 2003 del Bureau of Immigration and Customs Enforcement (ICE), una agencia dedicada a investigar y aprehender actividades criminales de extranjeros dentro de territorio estadounidense, marca un cambio de enfoque en las políticas de control migratorio en Estados Unidos. Hasta ese entonces, las políticas migratorias estaban mayormente enfocadas en estrategias de disuasión de entrada de migrantes irregulares en la frontera; estrategia que fue complementada con la detección, aprehensión y deportación de migrantes en todo el territorio estadounidense. Doce años más tarde, esta estrategia tuvo como resultado la llegada a la frontera norte de México de personas deportadas con largas estancias de residencia en Estados Unidos, en algunos casos de hasta diez años. En 1995, 83.8 por ciento de las personas mexicanas no permanecieron ni un día en territorio estadunidense antes de ser detenidas. Para 2005, este porcentaje ya mostraba un descenso notable registrando un 59.2 por ciento. Para el 2015, se han revertido los tiempos de estancias de las personas deportadas en relación a 1995, siendo el tiempo de estancia de menos de un día el de menor porcentaje con un 8.1 por ciento. En la actualidad, un 23.8 por ciento de los migrantes mexicanos deportados tenían más de un año de estancia en Estados Unidos. De éstos, un 75.4 por ciento contaba con más de tres años de estancia en Estados Unidos. 


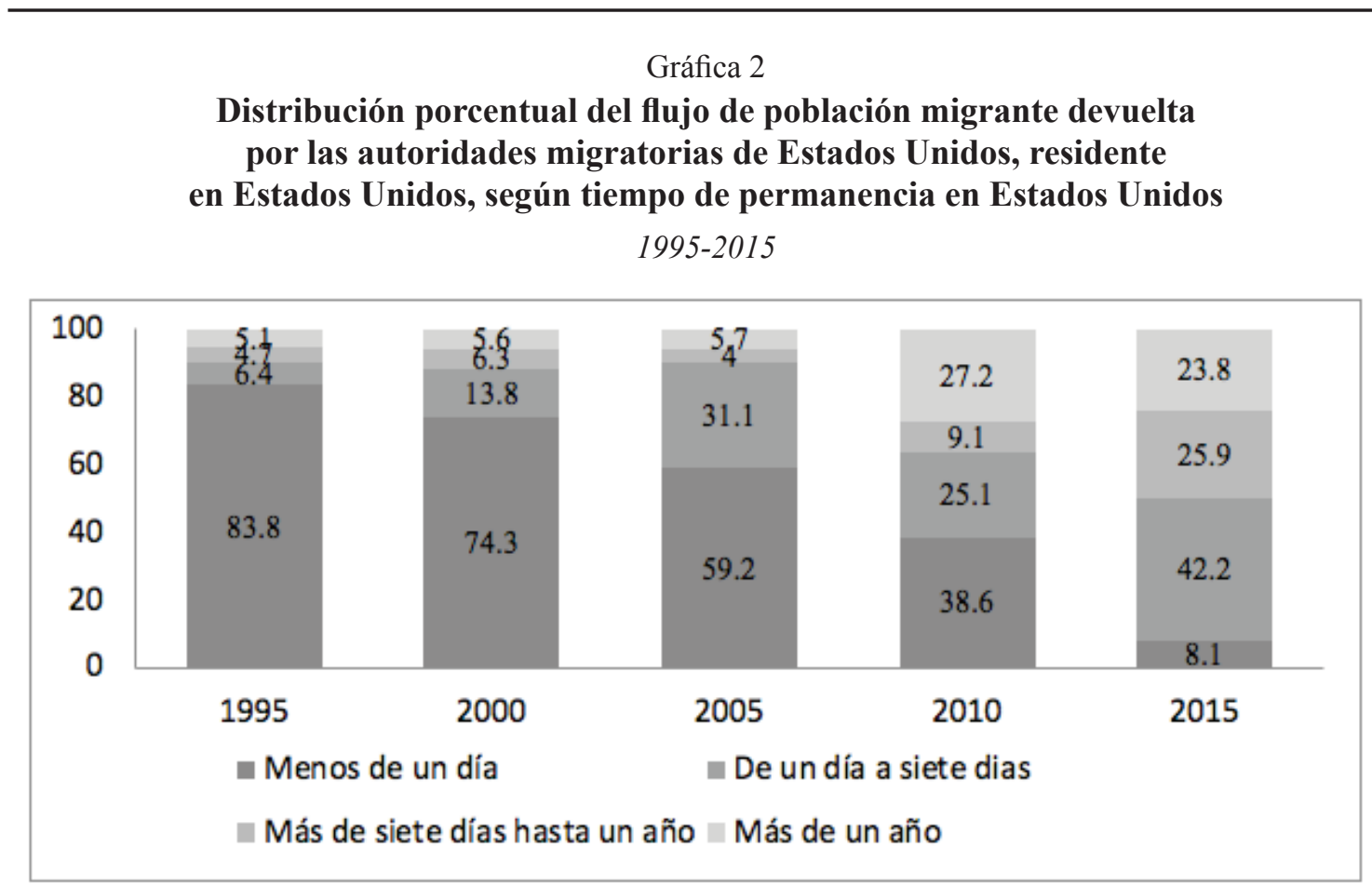

Fuente: Elaboración propia con datos de la Encuesta sobre Migración en la Frontera Norte, 1995, 2000, 2005, 2010 y 2015.

5.3. Hecho alternativo: se están deportando a personas con antecedentes criminales, lo que representa un peligro para las ciudades de la frontera norte de México. Realidad: se están deportando a personas que han cometido delitos menores.

La figura legal que aplican las autoridades migratorias estadunidenses para detener y deportar a migrantes mexicanos bajo la etiqueta de criminales, es muy amplia y en su mayoría se trata de faltas menores que incluso en México son de carácter administrativo y no penal. La gran mayoría de las personas deportadas con estancias de un año o más en Estados Unidos, es detenida cuando su situación migratoria irregular es detectada por cometer infracciones de tránsito, por cometer delitos menores o durante inspecciones policiacas rutinarias. Durante 2015, un 24 por ciento de las personas deportadas fue detenida por la policía como parte de inspecciones rutinarias. En 2015, el crimen de mayor recurrencia dentro de la población deportada bajo estatus criminal fue manejar en estado de ebriedad con un 19 por ciento (gráfica 3). 


\section{Gráfica 3}

Distribución porcentual del flujo de población mexicana deportada por autoridades de EUA que residen en ese país, por principal motivo de detención

2015

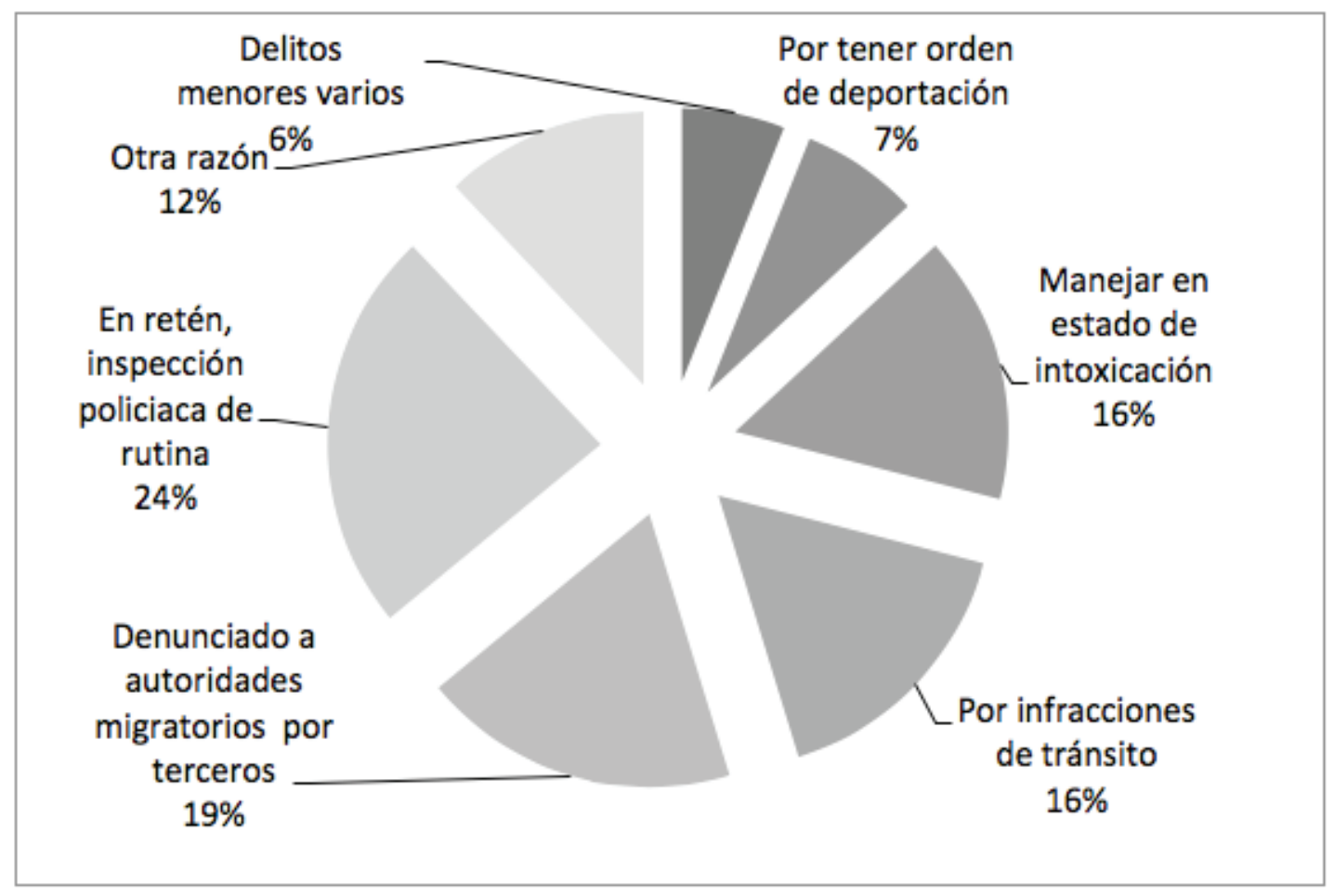

Fuente: Elaboración propia con base en la Encuesta sobre Migración en la Frontera Norte, 2014-2015.

5.4. Hecho alternativo: el aumento en el número de deportaciones de población mexicana traerá consecuencias graves, nunca antes experimentadas, en la frontera norte. Realidad: el aumento en el número de deportaciones de población mexicana tendría que alcanzar niveles nunca antes registrados para generar una situación inédita en la frontera.

Cualquier escenario de aumento en las deportaciones y su impacto en la frontera norte, tiene que partir del hecho de que el monto de las deportaciones de migrantes mexicanos se encuentra en su nivel más bajo desde hace 15 años. Mientras que, a principios de la década del 2000, las detenciones de migrantes mexicanos irregulares rebasaban el millón y medio de eventos, para 2016, la Patrulla Fronteriza de los Estados Unidos reportó 192,969 mil deportaciones de migrantes mexicanos (gráfica 4), Esto representa un descenso de más de $87 \%$ en las deportaciones de personas mexicanas. 
Gráfica 4

\section{Monto de detenciones de migrantes mexicanos realizadas por la Patrulla Fronteriza}

2000-2016

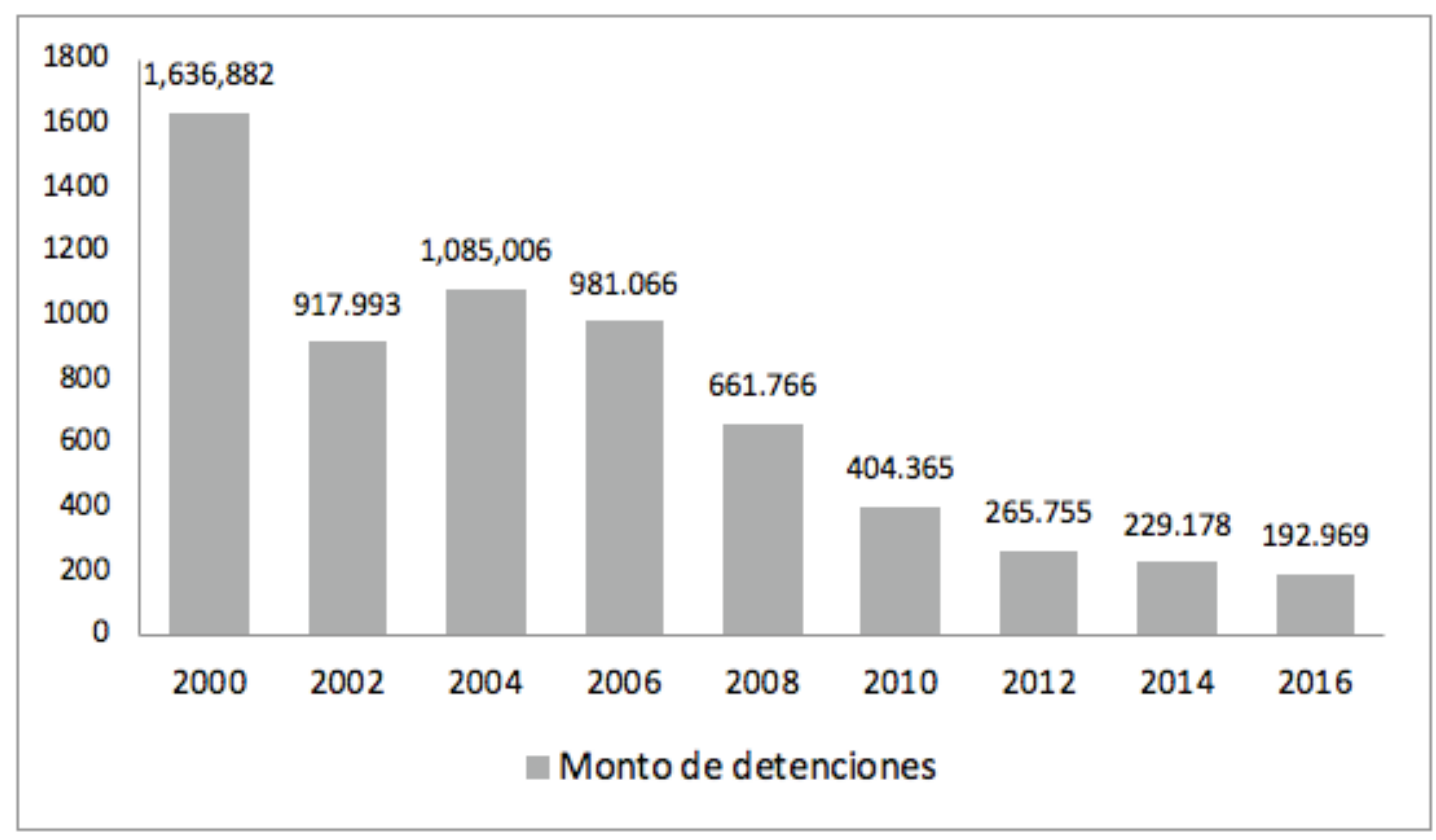

Fuente: Elaboración propia con base en datos de United States Border Patrol, 2000, 2002, 2004, 2006, 2008, 2010, 2012, 2014 y 2016.

El descenso en el retorno de población mexicana migrante es aún más contundente si tomamos como referencia los eventos de repatriación realizados por el Instituto Nacional de Migración (INAMI), Los eventos de repatriación realizados por el INAMI durante el 2015 son los menores en veinte años. De acuerdo a la gráfica 5, en 1995, el INAMI registró 853,365 mil repatriaciones, descendiendo en 2015 a 207,398 mil.

Sin duda, un aumento en las deportaciones de migrantes mexicanos va a representar retos importantes para la frontera norte de México. No obstante, lo observado durante los dos primeros meses de 2017 indica que el flujo de migración irregular mexicana hacia Estados Unidos va a descender aún más. Es de esperarse que sean cada vez menos las personas en México que pretender emigrar a un país cuyo presidente los ha señalado como criminales.

En este sentido, la orden ejecutiva de control migratorio para la frontera norte se puede considerar como un éxito incluso antes de ser implementada en su totalidad. Esto incluso nos hace pensar que contrario a los escenarios que se despliegan en algunos medios de comunicación en México, las deportaciones no solamente no van a aumentar de manera considerable, sino que incluso pueden ser eventualmente menores a las realizadas durante la administración de Obama. Lo que 
sí es una certeza es que cualquier aumento en deportaciones va a ser a expensas de esa población mexicana que ya se encuentra establecida en Estados Unidos por años.

\section{Gráfica 5}

\section{Eventos de repatriación de mexicanos desde Estados Unidos}

1995-2015

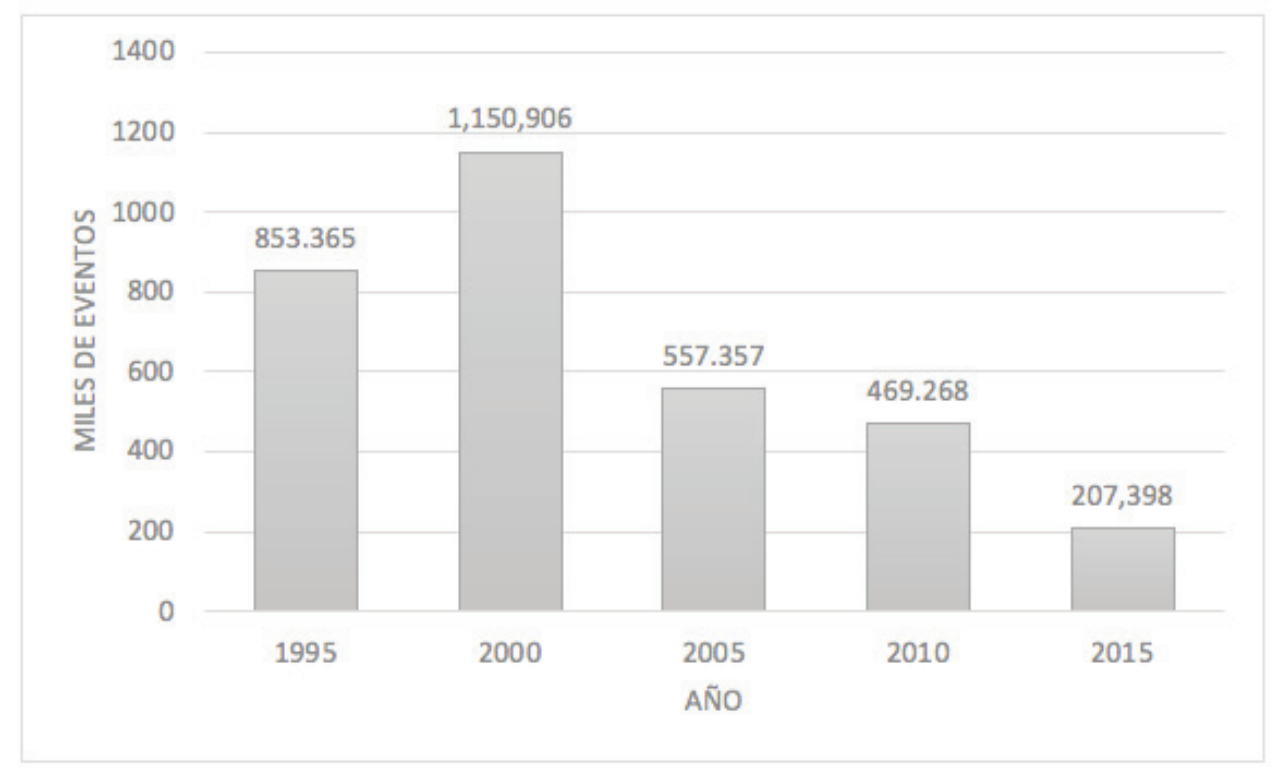

Fuente: Elaboración propia con base en Unidad de Politica Migratoria, SEGOB, 1995, 2000, 2005, 2010, 2015.

Por lo tanto, el tema central para los gobiernos y las sociedades fronterizas en México con respecto a este tema, no es exactamente en la cantidad de deportaciones, sino en reconocer los cambios que la migración mexicana irregular ha experimentado. En particular, reconocer que se trata de una población heterogénea en perfiles sociodemográficos, situación migratoria y necesidades después de la deportación. Las personas deportadas en la franja fronteriza durante la década de los noventa, muestran diferencias marcadas en cuestión de trayectoria migratoria y perfil demográfico con las personas aprehendidas por ICE afuera de sus casas diez años más tarde. Estas últimas personas representan las deportaciones de mayor aumento en años recientes. La lectura y operacionalidad que la administración Trump está realizando de la actual política migratoria, va más allá de cuestiones de control migratorio para acercarse peligrosamente a estrategias de control poblacional con un objetivo en mente: la inhibición del crecimiento de la población de origen mexicano en Estados Unidos. Así lo sugieren las órdenes ejecutivas del 25 de enero y posterior intención de crear una nueva agencia de gobierno nombrada Victims of Immigration Crime Engagement, encargada, según Trump, de dar "voz" a las víctimas de crímenes cometidos por inmigrantes indocumentados. 
En consecuencia, el desafío para el gobierno mexicano es recomponer su política migratoria de asistencia a población mexicana en Estados Unidos tomando en consideración las necesidades particulares de los diferentes sectores que conforman a la población mexicana que vive en Estados Unidos. Las eficiencia y eficacia de estrategias de apoyo de corte asistencialista y de corto plazo que hasta la fecha componen la mayoría de los programas de atención a población deportada ya han sido rebasadas por la realidad.

Esta recomposición debe de partir de reconocer que el apoyo a las personas deportadas tiene que presentarse antes de la deportación y no solamente al momento de la repatriación. Una mayor inversión en los programas de módulos de información y asistencia a mexicanos operados a través de los consulados en México es un comienzo atinado desde la esfera del gobierno federal. De manera similar, los gobiernos locales de la frontera norte de México tienen que trabajar con las comunidades mexicanas establecidas en Estados Unidos para idear maneras de apoyarlos en proteger su vida, patrimonio y familia en Estados Unidos.

\section{Referencias bibliográficas y documentales}

Encuesta sobre Migración en la Frontera Norte, El Colegio de la Frontera Norte, Secretaría del Trabajo y Previsión Social, Consejo Nacional de Población, Unidad de Política Migratoria, Secretaría de Relaciones Exteriores, Consejo Nacional para Prevenir la Discriminación, Secretaría de Desarrollo Social, Encuesta sobre Migración en la Frontera Norte de México, Disponible en: www.colef.mx/emif.

Executive Order: Enhancing Public Safety in the Interior of the United States, The White House Office of the Press Secretary Consultado el 27 de febrero de 2017. Disponible en: https://www.whitehouse.g the-press-office/2017/01/25/presidential-executive-order-enhancing-public-safety-interior-united.

Executive Order: Border Security and Immigration Enforcement Improvements, The White House Office of the Press Secretary. Consultado el 27 de febrero de 2017. Disponible en: ttps://www.whitehouse gov/the-press-office/2017/01/25/executive-order-border-security-and-immigration-enforc ment-improvements.

United States Border Patrol. Illegal Alien Apprehensions from Mexico by fiscal year, www. Consultado el 24 de febrero de 2017. www.cbp.gov/sites/default/files/assets/documents/2016-Oct/BP\%2 Total\%20Apps\%2C\%20Mexico\%2C\%20OTM\%2 FY2000-FY2016.pdf. Consultado el 24 de febrero de 2017. Unidad de Política Migratoria, SEGOB, Evento de repatriación de mexicanos desde Estados Unidos, según entidad federativa y punto de recepción, 1995-2015. 


\section{Gobierno de Trump y los acuerdos internacionales sobre el cambio climático.}

María de Lourdes Romo Aguilar ${ }^{10}$

El 4 de noviembre de 2016 entró en vigor el Acuerdo de París donde se busca fortalecer la respuesta a la amenaza del cambio climático tratando de mantener el aumento de la temperatura mundial por debajo de $\operatorname{los} 2^{\circ} \mathrm{C}$. Entre los países firmantes se encuentran México y Estados Unidos de América (EUA). Sin embargo, el actual Presidente de EUA está buscando la manera de abandonar el acuerdo de París ratificado por más de cien países.

Por ello, el objetivo de este apartado es analizar la postura de rechazo a las evidencias del cambio climático del presidente Donald Trump y sus consecuencias en los acuerdos internacionales, acciones y programas en marcha en México y en particular en su Frontera Norte.

El presidente Trump se ha referido al cambio climático como un invento, algo que no existe, "un cuento chino" porque señala que es una farsa concebida por China, algo inventado, una especie de conspiración. Esta postura es muy preocupante ya que EUA es el segundo máximo emisor de gases efecto invernadero (GEI) después de China, recordemos que los GEI son fundamentales en el aumento de la temperatura. No obstante diversos estudios y grupos de científicos han señalado y reiterado las evidencias claras y contundentes de la existencia real del cambio climático, sin lograr impactar en el cambio de perspectiva del presidente Trump, esto es evidente a partir de la prohibición a trabajadores de la Agencia de Protección Ambiental (EPA) de hablar sobre el cambio climático, en otro hecho de censura la cuenta oficial del Badlands National Park "ha borrado sus mensajes en Twitter donde informaba sobre el calentamiento global" (Hipertextual, 25 enero 2017), Reuters agencia de noticias, señala que Trump ha pedido a la EPA que elimine la sección de cambio climático de su página web, sin embargo cuando esto se dio a conocer se dio marcha atrás.

En la página electrónica de la Casa Blanca difícilmente se encuentra algo sobre el cambio climático, pero sí se considera como un tema relevante El Primer Plan sobre Energía de América, donde la administración de Trump busca una política que disminuya costos de mano de obra y maximice el uso de los recursos para independizarse del petróleo extranjero, con ello busca también eliminar las que considera políticas dañinas e innecesarias tales como el Plan de Acción Climática y plantea redirigir la misión esencial de la EPA en relación con la protección de aire y agua. Sin embargo, este planteamiento desconoce totalmente el impacto del cambio climático y se olvida que la EPA es la Agencia para la protección del ambiente lo que incluye todos los recursos naturales, pero también y por supuesto al ser humano. Esta política energética supone un aumento en las emisiones de $\mathrm{CO} 2$. El presidente Trump estuvo anunciando en repetidas ocasiones que retira-

${ }^{10}$ Correo electrónico:lromo@colef.mx. 
ría EUA del Acuerdo de París lo que lo libraría del compromiso signado de cuatro años y lamentablemente lo cumplió. En junio de 2017 se anunció la salida de Estados Unidos de Norteamérica del acuerdo de París sobre Cambio Climático, con esto este país ha dejado de ser un aliado del planeta y manifiesta de manera evidente su rechazo a las evidencias científicas sobre este cambio climático y sin duda con ello profundiza aún más la distancia con Europa.

El impacto de la salida del Acuerdo de París, de forma inmediata se reflejará en el retiro de recursos económicos comprometidos a México para combatir el cambio climático en este año, y de manera particular en la Frontera México-Estados Unidos la política de la actual administración de EUA para promover el uso de combustibles fósiles generaría grandes problemas con el agua en las ciudades fronterizas por la posible contaminación que causa la extracción de dichos combustibles, recordemos que el agua es uno de los recursos compartidos de forma binacional y no se pueden tomar decisiones unilaterales, por ello la negociación binacional en cuestiones ambientales debe ser más decidida y enérgica sobre la base de la relevancia de los recursos compartidos y la conveniencia de su aprovechamiento sustentable por parte de ambas naciones, se ha avanzado mucho en materia de gestión binacional del medio ambiente de la frontera México-Estados Unidos, no se debe dar marcha atrás y los gobernadores de los estados fronterizos del norte de México requieren tomar un papel proactivo y de colaboración conjunta para incidir en la tónica de la negociación binacional en el tema ambiental.

\section{Referencias bibliográficas y documentales}

Hipertextual, https://hipertextual.com/2017/01/trump-censura-cambio-climatico, consultado el 18 de de marzo de 2017. 


\section{? 7. Cambio climático y seguridad hídrica y Donald Trump.}

Alfonso Andrés Cortez Lara ${ }^{11}$

Desde finales de la década de los noventas, la disponibilidad y acceso al agua se ha tornado en una situación crítica en muchas partes del mundo convirtiéndose así en uno de los grandes desafíos de la humanidad. Con mayor frecuencia, su disponibilidad geográfica contrastada con el crecimiento de la población y las actividades económicas en diferentes regiones del planeta, particularmente en las zonas áridas y semiáridas, crea condiciones de tensión y conflicto entre las diferentes regiones y sectores de usuarios.

Frecuentemente, tres aspectos centrales surgen en las discusiones sobre el tema tanto a nivel global como regional y local: primero, el concerniente a la amenaza y complejidad adicional que representa el cambio climático; segundo, el fuerte vínculo que existe entre la seguridad hídrica, alimentaria y energética tal que resulta inoperante tratarlos por separado tanto en la práctica como en las políticas públicas; y tercero, la imperiosa necesidad de que estos vínculos consideren una perspectiva integral, gobernanza efectiva, planeación y manejo de recursos hídricos que incorporen cabalmente la implementación de procesos adaptativos, flexibles y más descentralizados.

El concepto de seguridad hídrica, en su acepción más amplia, significa asegurar la disponibilidad del agua en términos de cantidad, calidad y oportunidad a un costo justo y razonable tanto para el abastecimiento humano como para los usos de subsistencia, la protección de los ecosistemas y los diferentes procesos de producción. Más aún, el reto de enfrentar el cambio climático exige también que las estrategias para alcanzar la seguridad hídrica consideren la mejora en las capacidades institucionales, financieras y de desarrollo de infraestructura física para acceder y utilizar el agua de forma sustentable además de manejar las interrelaciones entre los diferentes usos y sectores productivos que compiten fuertemente por el mismo recurso base del desarrollo generalmente asignado o comprometido en su totalidad.

Tanto a nivel global como nacional, es importante asegurar la producción de alimentos en un contexto de escasez natural o construida tomando en cuenta que este sector utiliza en promedio el $77 \%$ de la disponibilidad total de agua en las zonas áridas y semiáridas y enfocarse más en la eficiencia de uso del agua y la energía, a la vez que se implementan fuentes alternas de producción de energías limpias, como la eólica y solar, a efecto de reducir la demanda y el consecuente impacto en el medio ambiente. Al final del día, las políticas públicas del sector hídrico deben priorizar el impulso de acciones tendientes a alcanzar, entre otras, una de las principales Metas de Desarrollo Sustentable 2030 que se refiere a la mitigación de los efectos del cambio climático.

\footnotetext{
${ }^{11}$ Correo electrónico: acortez@colef.mx.
} 
El marco institucional para el reparto del agua disponible en las cuencas transfronterizas entre México y los Estados Unidos es el Tratado para la Utilización de las Aguas de los Ríos Colorado, Tijuana y Bravo firmado por ambos gobiernos en febrero de 1944. El Tratado de Aguas Internacionales ha tenido una notoria evolución que se observa en las 320 Actas firmadas a la fecha por la Comisión Internacional de Límites y Aguas, cuerpo técnico-diplomático binacional responsable de la aplicación y gestión de los acuerdos derivados de dicho Tratado y cuyas Actas más recientes enfatizan los aspectos de cooperación binacional para la protección ambiental y para enfrentar la amenaza del cambio climático.

Al tratarse de cuencas hídricas transfronterizas internacionales, las tareas de cooperación se tornan complejas toda vez que entran en juego factores restrictivos como las diferencias en las políticas hídricas, económicas y sociales de cada país. La región de la frontera México-Estados Unidos es un caso único tanto por los contrastes tan marcados que se observan en los sistemas político-administrativos y esquemas económicos, sociales y culturales que confluyen en ella, como por la dinámica de crecimiento poblacional acelerado que ha mostrado a partir de la década de los años sesenta mismo que induce una profundización de la problemática en torno a los recursos hídricos compartidos.

En los 73 años que han transcurrido desde la firma del Tratado de Aguas Internacionales, la dinámica de la región ha transformado significativamente el panorama de oferta y demanda de agua. A lo anterior se suman los efectos del cambio climático, cuya severidad se pronostica con la presencia de eventos extremos como sequías prolongadas ó inundaciones cada vez con mayor frecuencia en los años por venir.

Lo anterior, crearía nuevas condiciones de conflicto, no solo entre usuarios, sino entre regiones y entre países tal como ha ocurrido a lo largo de la historia de la relación binacional, tanto cuando el agua escasea o cuando se presenta en abundancia hechos que se pueden ejemplificar con las inundaciones a principios del siglo pasado, la salinidad en los $60 \mathrm{~s}$, el arrastre y acumulación de sedimentos en los 90s y las divergencias por la decisión unilateral de la construcción de obras hidráulicas estratégicas como el revestimiento del Canal Todo Americano en la frontera Californiana en la década pasada.

Respecto a dichos pronósticos de cambio climático, se anota que desde finales de 1999 inició un periodo de sequía prolongada en la cuenca del río Colorado, uno de los periodos más significativos en el último siglo lo que ha obligado a los ocho estados usuarios de la cuenca a encontrar innovadoras medidas de cooperación para el manejo de la demanda hídrica y la protección del medio ambiente, tal como se establece en el Acta 319 del Tratado de Aguas Internacionales firmada en noviembre del 2012 y que deberá dar lugar a nuevas Actas adicionales para atender otras regiones de la frontera en donde se ve amenazada la seguridad hídrica a nivel local, regional e internacional. 
Los procesos antes mencionados para seguir enfrentando éstos retos de manera colaborativa y en un marco de cooperación estrecha, se ven amenazados con los nuevos enfoques anunciados por la administración federal del Presidente Donald Trump y la notoria descompostura de las relaciones bilaterales que ponen en riesgo tanto los avances que hasta la fecha se habían alcanzado en años recientes así como la continuidad de los procesos de cooperación al establecer dicha administración dos cambios notorios en los enfoques que hasta hoy guían las relaciones en materia de gestión y manejo de aguas transfronterizas: uno, la intención de renegociar el TLCAN y, con ello, la posible modificación de los aspectos ambientales que promueven, desarrollan y financian proyectos de infraestructura ambiental y de conservación de recursos hídricos en la zona fronteriza; y dos, el enfoque distinto de la administración Trump con respecto al tema de Cambio Climático, aspecto éste que representa el fundamento de las recientes negociaciones en materia de manejo de aguas transfronterizas.

Estas modificaciones que realiza la administración del Presidente Trump, se pueden traducir en que probablemente veremos en los próximos meses mayor tensión en el tratamiento de temas referentes a las aguas compartidas entre ambos países. Ello a su vez implica que los agentes negociadores del lado mexicano aprovechen de una manera mucho más amplia los mecanismos de respaldo social de las comunidades, mecanismos que, para el caso de la CILA, afortunadamente ya se han iniciado a través de los Foros Ciudadanos para tratar de manera oportuna temas relevantes en el ámbito local para evitar conflictos o, en su caso, resolverlos de manera adecuada y benéfica para las partes involucradas. 


\section{El destino de los recursos naturales compartidos: agua.}

Gustavo Córdova Bojórquez ${ }^{12}$

Desde la firma del Tratado de Guadalupe Hidalgo en 1848, los límites entre México y los Estados Unidos quedaron marcados por el cauce del Río Bravo y un vasto territorio al oeste que va desde Ciudad Juárez hasta Tijuana. La nueva frontera se caracteriza por la escasez del recurso debido a su posición geográfica donde se encuentran regiones biogeográficas con poca agua como la de California, el Desierto Sonorense, el Desierto Chihuahuense y la Planicie Tamaulipeca (Morrone, 2005) y en la cual se presentan sequías recurrentes (Ortega-Gaucín, 2013). Contribuye a esta escasez, la demanda cada vez mayor del líquido a partir del desarrollo de la región en 1965 con el Programa de Industrialización de la Frontera y con la firma del Tratado de Libre Comercio de América del Norte (TLCAN) en 1994 (López-Villafañe, 2004).

El destino del recurso hídrico queda entonces supeditado al manejo eficiente vía la cooperación por parte de los gobiernos de ambos lados. El manejo abarca el trabajo constante en la Cuenca del Río Colorado, la Cuenca del Río Grande/Bravo, los acuíferos binacionales y embalses de gran magnitud como la Presa Hoover en Nevada, la Presa El Elefante en Nuevo México, la Presa La Boquilla en Chihuahua, la Presa La Amistad en Del Río Texas y Acuña, Coahuila y La Presa Falcón en Reynosa, Tamaulipas y McAllen, Texas. Al final, son las fuentes principales de agua para el mantenimiento de ecosistemas y para el soporte de todas las actividades humanas, no sólo de las comunidades fronterizas, sino de lugares alejados de la frontera como es la ciudad de Los Ángeles, California que recibe agua del Río Colorado. En general, la disponibilidad de agua tanto superficial como subterránea en relación con la demanda ya llegó a su nivel de equilibrio y, en algunas zonas, se presentan un déficit alarmante del líquido como en la zona de Tijuana-San Diego, Juárez-El Paso, la zona Metropolitana de Monterrey y ambos Nogales (Sonora-Arizona).

Gracias a la intervención de organismos binacionales como la Comisión Internacional de Límites y Aguas (IBWC por sus siglas en inglés) creada en 1944, la Comisión de Cooperación Ecológica Fronteriza (BECC, por sus siglas en inglés) creada en 1994 y el grupo de trabajo del agua del Programa Ambiental México Estados Unidos Frontera 2012 hoy 2020, creado en 2006 y organismos nacionales como la Junta Ambiental del Buen Vecino que es un comité federal independiente de asesoría cuya misión es dar a conocer al Presidente y al Congreso de los Estados Unidos acerca de prácticas a lo largo de la frontera de los Estados Unidos, se han podido encontrar mecanismos de cooperación de gran alcance con recomendaciones conjuntas, teniendo a bien el beneplácito de actores no gubernamentales, que tratan de influir en las políticas públicas de cada lado para asegurar el recurso hídrico.

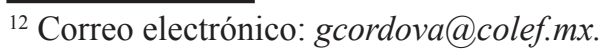


La llegada de Donald Trump a la presidencia de los Estados Unidos, representa un futuro incierto sobre la seguridad de los recursos hídricos de la frontera México-Estados Unidos. Hasta ahora, el discurso del Presidente Trump no ha sido conciliador para con el gobierno mexicano y su posición respecto a temas ambientales es difícil de dimensionar, en especial cuando rechaza unilateralmente los Acuerdos de París de 2016 relacionados con el cambio climático global y ha avanzado en su idea de ampliar el muro fronterizo con la comprobada afectación a especies animales en corredores biológicos transfronterizos (Ganster, 2007).

El destino de los recurso hídricos en la frontera queda supeditada, sin duda, a la cooperación ya que los logros en materia de manejo de agua superficial como la distribución de agua mediante el Tratados de Agua de 1906 para la región del Valle de Juárez y El Paso Texas, el Tratado de agua de 1944 para el Río Colorado y Río Bravo, los acuerdos para el manejo las presas internacionales como la Amistad y Falcón, la administración de cuatro plantas de tratamiento de aguas residuales de carácter binacional y las 322 Actas (acuerdos binacionales) de la CILA, más las minutas de las reuniones de los grupos de trabajo del agua y el Foro de Política del Agua del Programa Ambiental México Estados Unidos Frontera 2020, entre otros espacios públicos, son producto del diálogo, la deliberación, el intercambio de información de todos los niveles de gobierno, el consenso, pero en especial, de la participación de actores y sectores que se han visto involucrados en las dinámicas de formulación de políticas públicas y que no aceptarían, decisiones verticales y altamente racionales de comando y control por cualquiera de los gobiernos.

Esperamos haya prudencia por parte del Presidente Trump y comprenda que la buena vecindad en materia hídrica es un proceso en constante construcción, con lentos avances y puede haber grandes retrocesos si mantiene una posición de no ver y escuchar a actores y sectores de ambos lados de la frontera que se han esforzado por vivir en armonía con sus recursos naturales.

\section{Referencias bibliográficas y documentales}

Ganster, P. (2007). "La protección ambiental y la seguridad en la frontera México-Estados Unidos: el asunto del muro fronterizo analizado en contexto", en Una Barrera a nuestro ambiente compartido. El muro fronterizo entre México y Estados Unidos, A. Córdova y C. De la Parra (eds.), México, D.F. SEMARNAT-INE, El Colegio dela Frontera Norte y Consorcio de Investigación y Política Ambiental del Suroeste.

López-Villafañe, V. (2004). "La industrialización de la frontera norte de México y los modelos exportadores Asiáticos", en Comercio Exterior, (54) 8, 674-680.

Morrone, Juan, 2005, "Hacia una síntesis biogeográfica de México", en Revista Mexicana de Biodiversidad, (76) 2, 207-252, URL: http://www.scielo.org.mx/scielo.php?script=sci_arttext\&p $d=S 1870-34532005000200006$, consultado el 08 de marzo e 2017.

Ortega-Gaucin, David, 2013, "Caracterización de las sequías hidrológicas en la cuenca del Río Bravo”, en Terra Latinoamericana, (31) 3, 167-180, URL: http://www.redalyc.org/pdf/573/57328903001.pdf, consultado el 8 de marzo de 2017. 


\section{$\rightarrow$ 9. Consideraciones finales.}

Este documento ha planteado una serie de argumentos y elementos que pueden incorporarse a la política pública a partir del trabajo decidido y conjunto de los gobernadores de los seis estados fronterizos de México para gestionar que la política nacional tome en cuenta las problemáticas y propuestas expresadas en este trabajo. En particular se recomienda atender los siguientes puntos:

La diplomacia mexicana debe cambiar procesos y prácticas discursivas de victimización a un enfoque pragmático que redefina el concepto de soberanía y la relevancia de la región fronteriza.

La seguridad fronteriza necesita privilegiar el uso de la inteligencia policiaca y reducir el uso de las fuerzas armadas.

Es necesario que el gobierno mexicano plantee las negociaciones con el gobierno de Estados Unidos el tema de las drogas prohibidas modificando el paradigma prohibicionista a uno regulacionista, en donde el enfoque sea el de salud pública sobre todo en países consumidores como Estados Unidos y México.

Para los gobiernos estatales de la Frontera Norte de México las estrategias de apoyo a la migración mexicana indocumentada tienen que estar basadas en datos reales y no en estereotipos negativos en ambos lados de la frontera.

Las estrategias de apoyo a personas deportadas deben establecerse antes de la deportación a través de la colaboración entre comunidades en ambos lados de la frontera y para las personas deportadas se tiene que transitar de un enfoque asistencialista a uno que potencialice sus capacidades y puedan ser aprovechadas para su beneficio y el de las comunidades que los reciban.

En materia ambiental ambos países deben ratificar aquellas políticas de carácter binacional que han dado resultado, especialmente en materia hídrica. Algunos de los acuerdos binacionales importantes que deben ratificar las acciones que de ellos derivan son: el Acuerdo de la Paz, los tratados de aguas compartidas y avanzar en la redefinición de programas y acciones como el Programa Ambiental México-Estados Unidos Frontera 2020, para asegurar los recursos naturales, mantener el equilibrio ecológico y la salud de la población.

El gobierno mexicano debe negociar con su contraparte estadounidense la continuidad y financiamiento de los programas ambientales fronterizos apoyados a través de fondos de la Agencia Ambiental de Estados Unidos (EPA por sus siglas en inglés) tomando en consideración la propuesta de disminución sustancial de recursos y programas para la frontera y la negativa de participar en el esfuerzo de combatir el cambio climático ante el rechazo de su existencia por demás probada.

De manera enfática es fundamental rechazar la construcción del muro fronterizo. México y Estados Unidos además de ser importantes socios comerciales los unen lazos afectivos y reales 
de amistad y parentesco de millones de estadounidenses de origen mexicano. Un muro como el que propone el presidente Trump es una señal hostil a su socio y está fuera de toda proporción a lo que sería una política productiva y civilizada entre socios comerciales y amigos. El muro amenaza con destruir la confianza y empatía de la población mexicana hacia la sociedad estadounidense cuya opinión favorable es del 66\% durante la administración de Barak Obama (Pew Research Center ${ }^{13}$ ); es decir, la integración económica ha logrado erradicar muchos prejuicios que los mexicanos tenían hacia los Estados Unidos - empatía que las acciones del presidente Trump está deshaciendo.

Un muro impenetrable no solamente es dañino para el medio ambiente sino también amenaza con deshacer todos los avances en materia ambiental y la arquitectura institucional que se ha creado desde la firma del TLCAN. Un muro no impedirá que los ciudadanos de Estados Unidos y México respiren un aire contaminado y malos olores, tampoco impedirá la contaminación del agua superficial y subterránea. El medio ambiente como un bien público transnacional requiere de cooperación, confianza e instituciones transnacionales.

Un muro como una política de interdicción para impedir el tráfico de drogas será un fracaso. Una política antidroga requiere de cooperación y confianza -contrario a lo que el muro produce - de ambas partes. El muro no impedirá que las drogas fluyan o estén disponibles siempre y cuando la demanda exista.

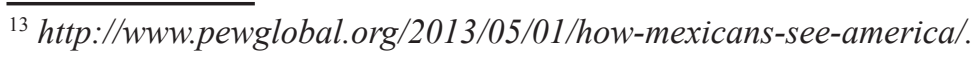


Números anteriores:

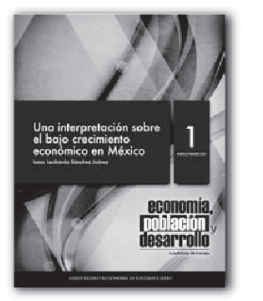

Economía, población y desarrollo.
Cuadernos de trabajo №1

Enero-Febrero 2011
Una interpretación sobre el bajo

crecimiento economico en México
Isaac Leobardo Sánchez Juárez

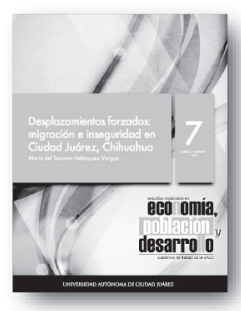

Economia, población y desarroll

Cuadernos de trabajo $\mathrm{N}$ -
Encro-Fcbrcro 2012

Desplazamientos forzados
migración e inseguridad

Ciudad Juárez, Chihuahua
Maria del Socorro Velázquez Varga

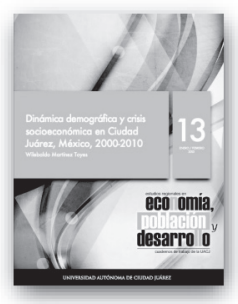

Economiá, población y desarrollo

de trabajo $N$

Dinámica demográ́fica y crisis
socieconómica en Ciudad Juáre Mexico, 2000-2010

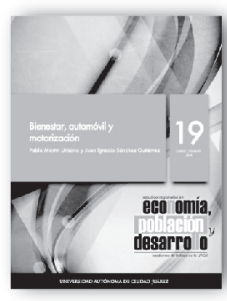

Economía, población y desarroll Enero - Febrero 2014 Bienestar, automóvil y motorización
Pablo Martín Urbano y Miosánchez Gutiérrez

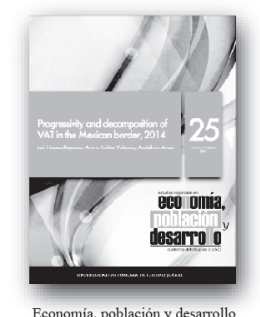

Cuadernos de trabajo No $_{0}$
Conomia,

Encro - Febrero 2015

Progressivity and decomposition of
VAT in the Mexican border, 2014 Abdelkim Araar

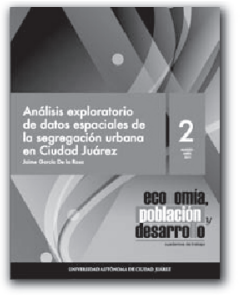

Economía, población y desarrollo.
Cuadernos de trabajo № 2

Marzo-Abril 2011

espaciales de la segregacón

Jaime Garcia De la Rosa

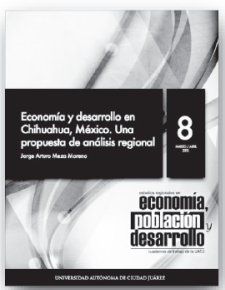

Economia, población y desarrollo

Cuadernos de trabajo №7

Economía y desarrollo en

propuesta de análisis regiona

Jorge Arturo Meza Moreno

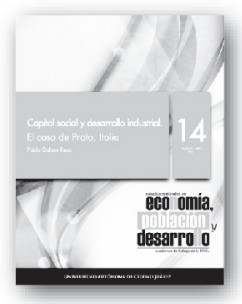

Economía, población y desarrollo

Marzo - Abri1 2013

Capital social y desarrollo

Pablo Galaso Reca

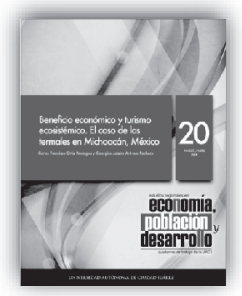

Economia, población y desarrollo

Marzo - Abril 2014

Beneficio económico y turismo

enico. El caso de las ter
en Michoacán, Mésico

arlos Franciseo Ortiz Paniagu

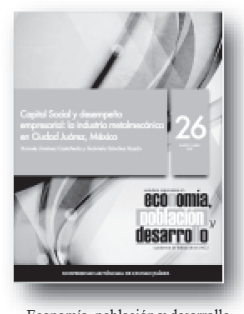

Economía, población y desarrollo

Cuadernos de trabajo № 26
Marzo - Abril 2015

Capital Social y desempeño empresa
la industria metalmecánica en

a industria metalmecánica en
Ciudad Juárez, México

Ramsés Jiménez Castañeda y
Gabriela Sáncez Bazán
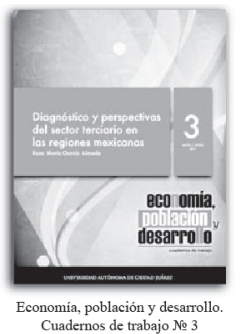

Diagnóstico y perspectivivas

regiones mexicanas
rosa Mária Garcia Almad

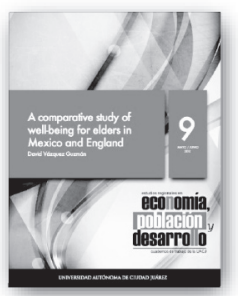

Economia, población y desarrollo

Cuadernos de trabajo № 9
Mayo - Junio 2012

A comparative study of

Mexico and England
David Vázquez Guzmán

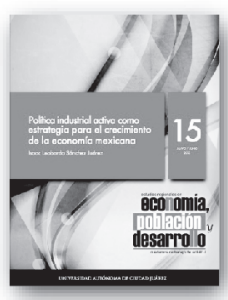

Economia, población y desarroll

Madernos de trabajo
Mayo - Junio 2013

Politica ind ustrial activa como

strategia para el crecimiento

Isaac Lcobardo Ś́nexicana
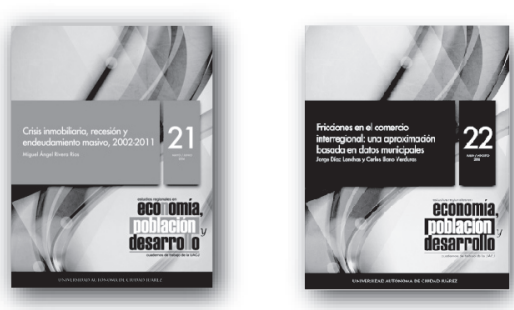

Economia, población y desarrollo

Cuademos de trabajo
Mayo - Junio 2014

Crisis inmobiliaria, recesión y
adeudamiento masivo, $2002-2011$

Miguel Ángel Rivera Rios

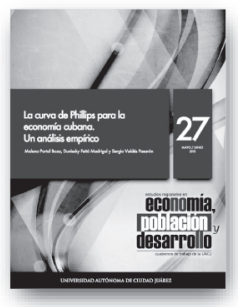

Economia, población y desarrollo

Cuadernos de trabajo № 27

a curva de Phillips para

economía cubana.

Malena Portal Boza, Duniesky Feitó

Economía, población y desarrollo.
Cuadernos de trabsio

julio-Agosto 201

Los indices IDH y FGT en la

mera década del siglo XX

Economía, población y decarrollo

Cuadernos de trabajo №
Julio - Agosto 2012

Political competition and the

edistribution in a federation

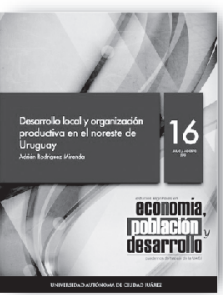

Economía, población y desarrollo

Cuadernos de trabajo №
Julio - Agosto 2013

Desarrollo local y organización
productiva en el noroeste de Urugu

Economía, población y desarrollo

Julio - Agosto 2014

Ficciones en el comercio

basada en datos municipales
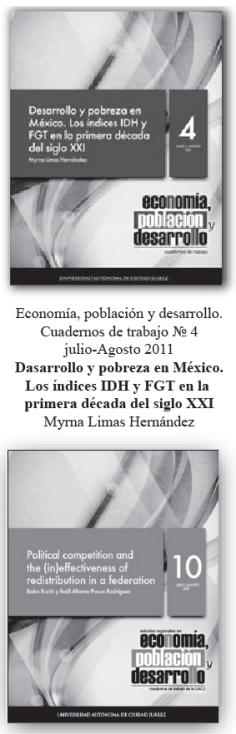

Jorge Diaz Lanchas y Carlos Llano Verduras
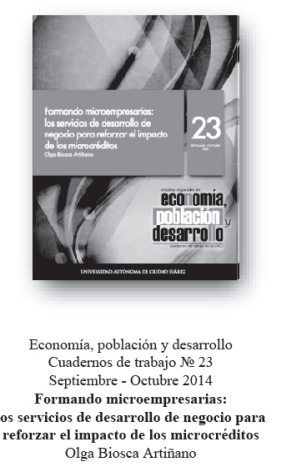

Cuadernos de trabajo № 24

El crecimiento de las regiones

el paradigma del desarrollo

divergente. Un marco térico
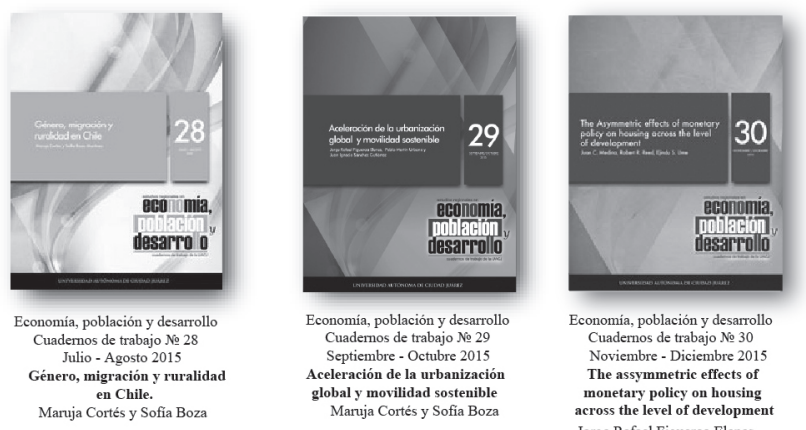

conomía, población y desarrol

Cuadernos de trabajo № 30

The assymmetric effects of

monetary policy on housing

Jorge Rafael Figueroa Elenes,

Juan Ignacio Sánchez Gutiérrez 
Números anteriores:
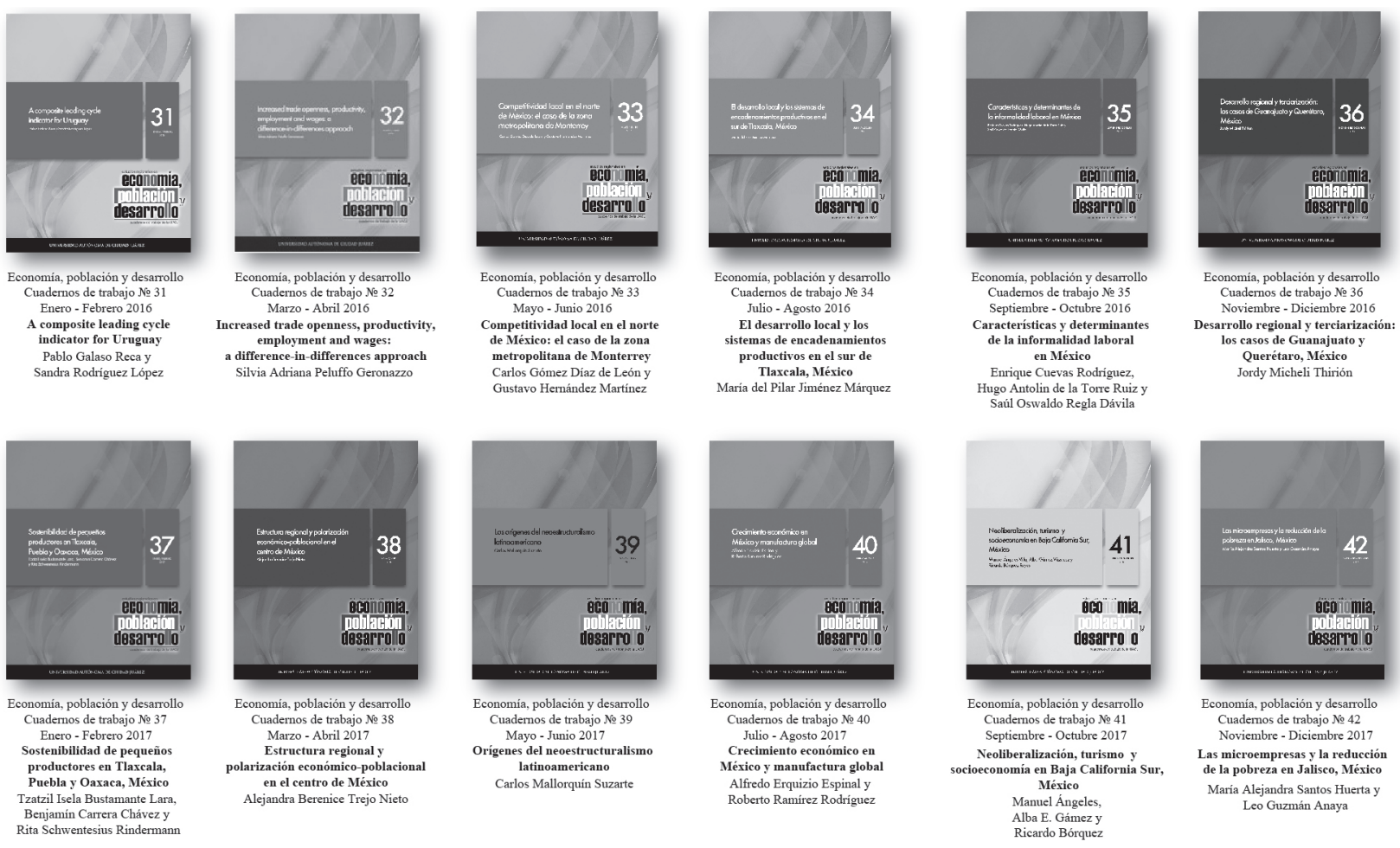

Cuadernos de trabajo № 42 Noviembre - Diciembre 2017 Las microempresas y la reducción
de la pobreza en Jalisco, México Maria Alcjandra Santos Hucrta y eo Guzman Anaya
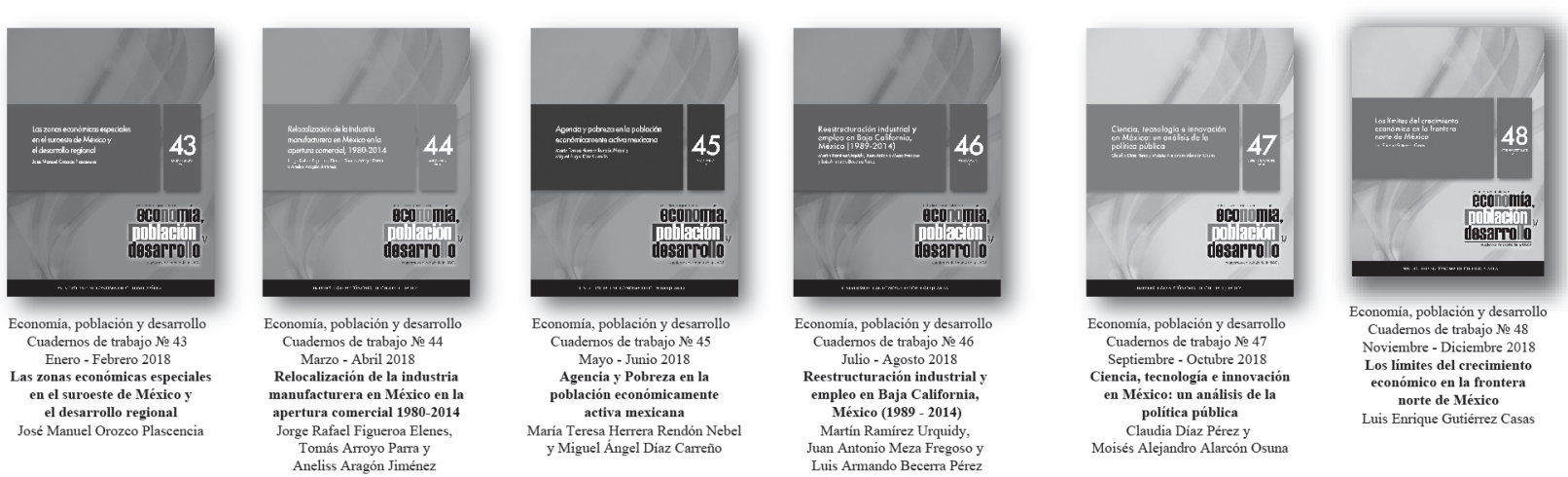


\section{$\rightarrow$ Normas Editoriales}

\section{Para el documento general:}

Tipo de letra: Times New Roman.

Tamaño: 11 puntos.

Interlineado: 1.5 espacios.

Títulos y subtítulos:

El texto principal en 11 puntos. Títulos 12 puntos (en resaltado). Subtítulos 11 puntos. Cada título y subtítulo deberá numerarse bajo el siguiente orden: $1,1.1,2,2.1,2.2 \ldots$

La extensión máxima de los cuadernos de trabajo será de 40 cuartillas.

La primera vez que se emplee una sigla en el texto se especificará primero su equivalencia completa y después la sigla.

\section{Hoja de presentación:}

Título:

14 puntos, centrado, resaltado.

Nombre de autor(es):

12 puntos

Resumen y abstract:

Debe incluir resumen en español y abstract (diez puntos), no mayor a 250 palabras

Palabras clave:

Incluir entre tres y cinco palabras clave, en español e inglés

Referencia del autor o autores:

Institución de adscripción, grado académico y líneas-grupos de investigación que desarrolla y a los que pertenece.

\section{Sistema de referencia de citas:}

Harvard-APA

Las citas bibliográficas en el texto deberán incluir entre paréntesis sólo el apellido del autor, la fecha de publicación y el número de página; por ejemplo: (Quilodrán, 2001: 33).

\section{Notación en sección de bibliografía y fuentes de información:}

Se deberá incluir al final del texto. Toda referencia deberá estar mencionada en el texto o notas de pie de página.

Cada referencia iniciará con el primer apellido o los apellidos, luego el nombre del autor, y después, entre paréntesis, el año de publicación seguido de un punto. Ejemplos:

Se deberá incluir al final del texto. Toda referencia deberá estar mencionada en el texto o notas de pie de página.

Cada referencia iniciará con el primer apellido o los apellidos, luego el nombre del autor, y después, entre paréntesis, el año de publicación seguido de un punto. Ejemplos:

Artículo:

Ros, Jaime (2008). “La desaceleración del crecimiento económico en México desde 1982”, en Trimestre Económico, vol. 75, núm. 299, pp. 537-560.

Libro:

Villarreal, René (2005). Industrialización, competitividad y desequilibrio externo en México. 
Un enfoque macroindustrial y financiero (1929-2010), México, Fondo de Cultura Económica. Capítulo de libro:

Castillo, Manuel Ángel (2003). "La política de inmigración en México: un breve recuento", en Manuel Ángel Castillo, Alfredo Lattes y Jorge Santibáñez (coords.), Migración y fronteras, Tijuana, El Colegio de la Frontera Norte / Asociación Latinoamericana de Sociología / El Colegio de México, pp. 425-451.

\section{Notas de pie de página:}

Se utilizarán para hacer indicaciones complementarias, aclaraciones o ampliación de una explicación. La notas de pie de página en Times New Roman, 10 puntos.

\section{Tipología de imágenes dentro del texto:}

Cuadro

Gráfica

Diagrama

Mapa

Figura

Todas las imágenes deben ser numeradas y mencionadas dentro del texto. A toda imagen debe incluirse la fuente.

Las indicaciones de la imagen: tipo y número de imagen, título de imagen y fuente se escriben en 10 puntos. En el texto poner como imagen los mapas, figuras, gráficas y diagramas -con el ánimo de no perder el formato realizado por el autor.

\section{Ecuaciones y fórmulas:}

Si se utilizan ecuaciones o fórmulas deberá utilizarse el editor de ecuaciones de Word y numerarse.

\section{Envío de trabajos}

Los trabajos deben ser enviados a la dirección de correo: lgtz@uacj.mx. Con el Dr. Luis Enrique Gutierrez Casas, editor de esta publicación.

La aceptación de cada colaboración dependerá de la evaluación de dos dictaminadores especialistas en la materia que se conservarán en el anonimato, al igual que el autor (autores) para efectos de la misma. 


\section{$\rightarrow$ Editorial Guidelines}

\section{For General Document:}

Font type: Times New Roman.

Size: font size 11.

Paragraph: 1.5 line spacing.

Titles and subtitles: Main text font size 11. Titles font size 12 (Bold). Subtitles font size 11.

Each title and subtitle should be numbered in the following order: 1, 1.1, 2, 2.1, 2.2...

The maximum length of the workbooks will be 40 pages.

The first time an abbreviation is used in the text will be specified first complete equivalence and then stands.

\section{Front cover:}

Title:

Font size 14, centered, Bold.

Author name(s):

Font size 12.

Abstract:

It should include abstract in Spanish and abstract (font size 10), no more than 250 words.

Keywords:

Include three to five keywords, in Spanish and English.

Reference of author:

Institution of affiliation, academic degree and line-developed by research groups and belonging.

\section{Bibliographical appointment system:}

Harvard-APA

Citations in the text should include between parentheses only the author's name, publication date and page number, for example:

(Quilodrán, 2001: 33).

\section{Notation about Bibliography section and Information fonts:}

Should be included at the end of the text. All references must be mentioned in the text or footnotes page.

Each reference starts with the first name or last name, then the name of the author, and then, in parentheses, the year of publication followed by a period. Examples:

Article:

Ros, Jaime (2008). “La desaceleración del crecimiento económico en México desde 1982”, en Trimestre Económico, vol. 75, núm. 299, pp. 537-560.

Book:

Villarreal, René (2005). Industrialización, competitividad y desequilibrio externo en México. Un enfoque macroindustrial y financiero (1929-2010), México, Fondo de Cultura Económica.

Book chapter:

Castillo, Manuel Ángel (2003). "La política de inmigración en México: un breve recuento”, en Manuel Ángel Castillo, Alfredo Lattes y Jorge Santibáñez (coords.), Migración y fronteras, Tijuana, El Colegio de la Frontera Norte / Asociación Latinoamericana de Sociología / El Colegio de México, pp. 425-451. 


\section{Footnotes:}

Must be used to make additional indications, clarification or expansion of an explanation. The footnotes must be in Times New Roman, font size 10.

\section{Image typology inside text:}

Picture

Graph

Diagram

Map

Figure

All images must be numbered and mentioned in the text, should include the source image. The indications of the image: type and number of image, image title and source are written in 10 font size. In the text set as image maps, figures, graphs and charts-with the intention of not losing the formatting by the author.

\section{Equations and Formulae:}

When using equations or formulas should be used in Microsoft Word equation editor and numbered.

\section{Paper sending}

Entries must be sent to the email address: lgtz@uacj.mx. With Dr. Luis Enrique Gutiérrez Casas, editor of this publication.

Acceptance of each collaboration will depend on the evaluation of two examiners skilled in the art to be kept anonymous, like the author(s) for the same purposes. 
Esta obra se editó y terminó de imprimir en Ciudad Juárez, Chihuahua, México 
Cuadernos de Trabajo de la Universidad Autónoma de Ciudad Juárez, número 49, enero - febrero de 2019

\section{Director y editor}

Dr. Luis Enrique Gutiérrez Casas

\section{Comité editorial}

Sección internacional

Dra. Sofía Boza Martínez (Universidad de Chile, Chile)

Dra. Olga Biosca Artiñano (Glasgow Caledonian University, Reino Unido)

Dra. Ángeles Sánchez Díez (Universidad Autónoma de Madrid, España)

Dr. Thomas Fullerton Mankin (University of Texas at El Paso, Estados Unidos)

Dr. Adrián Rodríguez Miranda (Universidad de la República, Uruguay)

\section{Sección local}

(Universidad Autónoma de Ciudad Juárez)

Dra. Myrna Limas Hemández

Dra. Ikuho Kochi

Dr. Raúl Alberto Ponce Rodríguez

Dr. Isaac Leobardo Sánchez Juárez

Dr. Héctor Alonso Barajas Bustillos 